NBER WORKING PAPER SERIES

\title{
WHAT DO WE KNOW ABOUT COMPETITION AND QUALITY IN HEALTH CARE MARKETS?
}

\author{
Martin Gaynor \\ Working Paper 12301 \\ http://www.nber.org/papers/w12301 \\ NATIONAL BUREAU OF ECONOMIC RESEARCH \\ 1050 Massachusetts Avenue \\ Cambridge, MA 02138 \\ June 2006
}

This paper was commissioned and supported by the Federal Trade Commission. The views and opinions expressed here are those of the author alone and do not necessarily represent the views or opinions of the FTC or any individual commissioner. Thanks are due to Ashish Arora, Nicolas Gravel, Paul Pautler, Mark Pauly, Carol Propper, Ray Rees, Lise Rochaix, Patrick Romano, Bill Sage, Alain Trannoy, Mike Vita, Bill Vogt, David Zimmer, Peter Zweifel, and participants at the Agency for Health Care Research and Quality and Federal Trade Commission conference "Provider Competition and Quality," held in Washington, D.C. in May 2003, and at the Third Annual Journ ées Louis-André Gérard-Varet, held in Marseilles in June 2004, for helpful comments and discussion. An earlier version of this paper was published as "Competition and Quality in Health Care Markets: What Do We Know? What Don't We Know?" in Économie Publique (Gaynor, 2004). I am grateful to Liz Fowler for editorial assistance. The usual caveat applies. The views expressed herein are those of the author(s) and do not necessarily reflect the views of the National Bureau of Economic Research.

(C2006 by Martin Gaynor. All rights reserved. Short sections of text, not to exceed two paragraphs, may be quoted without explicit permission provided that full credit, including (C) notice, is given to the source. 
What Do We Know About Competition and Quality in Health Care Markets?

Martin Gaynor

NBER Working Paper No. 12301

June 2006

JEL No. I1, L1, L3

\begin{abstract}
The goal of this paper is to identify key issues concerning the nature of competition in health care markets and its impacts on quality and social welfare and to identify pertinent findings from the theoretical and empirical literature on this topic. The theoretical literature in economics on competition and quality, the theoretical literature in health economics on this topic, and the empirical findings on competition and quality in health care markets are surveyed and their findings assessed.

Theory is clear that competition increases quality and improves consumer welfare when prices are regulated (for prices above marginal cost), although the impacts on social welfare are ambiguous. When firms set both price and quality, both the positive and normative impacts of competition are ambiguous. The body of empirical work in this area is growing rapidly. At present it consists entirely of work on hospital markets. The bulk of the empirical evidence for Medicare patients shows that quality is higher in more competitive markets. The empirical results for privately insured patients are mixed across studies.
\end{abstract}

\author{
Martin Gaynor \\ H. John Heinz III School of Public Policy and \\ Management \\ Carnegie Mellon University \\ Pittsburgh, PA 15213-3890 \\ and NBER \\ mgaynor@cmu.edu
}




\title{
What Do We Know About Competition and Quality in Health Care Markets?*
}

\author{
Martin Gaynor \\ H. John Heinz III School of Public Policy and Management \\ Carnegie Mellon University, \\ National Bureau of Economic Research, \\ Leverhulme Centre for Market and Public Organisation \\ University of Bristol
}

June 7, 2006

\begin{abstract}
The goal of this paper is to identify key issues concerning the nature of competition in health care markets and its impacts on quality and social welfare and to identify pertinent findings from the theoretical and empirical literature on this topic. The theoretical literature in economics on competition and quality, the theoretical literature in health economics on this topic, and the empirical findings on competition and quality in health care markets are surveyed and their findings assessed.
\end{abstract}

\footnotetext{
*This paper was commissioned and supported by the Federal Trade Commission. The views and opinions expressed here are those of the author alone and do not necessarily represent the views or opinions of the FTC or any individual commissioner. Thanks are due to Ashish Arora, Nicolas Gravel, Paul Pautler, Mark Pauly, Carol Propper, Ray Rees, Lise Rochaix, Patrick Romano, Bill Sage, Alain Trannoy, Mike Vita, Bill Vogt, David Zimmer, Peter Zweifel, and participants at the Agency for Health Care Research and Quality and Federal Trade Commission conference "Provider Competition and Quality," held in Washington, D.C. in May 2003, and at the Third Annual Journées Louis-André Gérard-Varet, held in Marseilles in June 2004, for helpful comments and discussion. An earlier version of this paper was published as "Competition and Quality in Health Care Markets: What Do We Know? What Don't We Know?" in Économie Publique (Gaynor, 2004). I am grateful to Liz Fowler for editorial assistance. The usual caveat applies.
}

Theory is clear that competition increases quality and improves consumer welfare when prices are regulated (for prices above marginal cost), although the impacts on social welfare are ambiguous. When firms set both price and quality, both the positive and normative impacts of competition are ambiguous. The body of empirical work in this area is growing rapidly. At present it consists entirely of work on hospital markets. The bulk of the empirical evidence for Medicare patients shows that quality is higher in more competitive markets. The empirical results for privately insured patients are mixed across studies.

\section{Introduction}

One of the most important industries in the United States economy is health care, accounting for nearly two trillion dollars in expenditure annually (Smith et al., 2006). The United States relies on markets for health care delivery and financing. As a consequence, antitrust enforcement is an important component of health care policy. This industry is also one in which competition is a real issue, given the extensive consolidation that has occurred in recent years (Gaynor and Haas-Wilson, 1999).

During the second half of the 1990s, a dramatic 
wave of hospital consolidation occurred in the United States. One source puts the total number of hospital mergers from 1994-2000 at over 900 deals (Jaklevic, 2002, and www.levinassociates.com), on a base of approximately 6,100 hospitals. Further, many local markets, including quite a few large cities such as Boston, Minneapolis, Pittsburgh, Philadelphia, St. Louis, and San Francisco (and others), have come to be dominated by 2-3 large hospital systems. Not surprisingly, many health plans have complained about rising prices as a result of these consolidations (Lesser and Ginsburg, 2001).

Table 1 provides statistics on concentration in hospital markets at 5 year intervals over the period 1985-2000. ${ }^{1}$ The table shows that the HerfindahlHirschmann Index $(\mathrm{HHI})^{2}$ for U.S. hospitals has been steadily increasing over time. In particular, the median HHI increased from 3,028 in 1985 to 3,995 in 2000. This is an increase of almost 1,000 points on a very large base. An HHI of 3,000 indicates a very concentrated market - for example, a market with three equally sized firms will have an HHI close to this value $(3,333)$. The FTC and DOJ consider markets with an HHI above 1,800 as highly concentrated. ${ }^{3}$ For highly concentrated markets such as these, the enforcement agencies consider any increase in the HHI of 100 points or more as presumptively anticompetitive (Federal Trade Commission and Department of Justice, 1992). The increase in median concentration from 1985 to 2000 is far greater than that threshold.

\footnotetext{
${ }^{1}$ These data are for metropolitan statistical areas (MSAs) only. This represents the vast majority of the population and hospitals in the U.S.

${ }^{2}$ The HHI is defined as the sum of firms' squared market shares, $H H I=\sum_{i=1}^{N} s_{i}^{2}$, where $s_{i}$ is firm i's market share, and $N$ is the number of firms. The HHI increases as the number of firms decreases or asymmetry of market shares increases. It has a maximum of 10,000 for a monopoly and has a minimum at $10,000 / N$, where the market is divided equally between $N$ firms.

${ }^{3}$ Markets with an HHI below 1,000 are considered unconcentrated, and those with an HHI between 1,000 and 1,800 are designated as moderately concentrated (Federal Trade Commission and Department of Justice, 1992). In practice, concentration levels higher than the cutoffs in the Guidelines are often tolerated (see Federal Trade Commission, 2004).
}

Hospital markets have been an active area of antitrust enforcement. Since 1984, the federal antitrust authorities have brought 11 suits seeking to block hospital mergers, and engaged in many other activities combating anticompetitive practices. ${ }^{4}$ The major emphasis in these cases has been effects on price. A major concern in health care, however, is effects on quality. ${ }^{5}$

Quality is of major concern in health care for a number of reasons. First, the effect of health care quality on an individual's well-being can be very great, and often will be more important than the quality of other goods or services. Second, due to the pervasive presence of insurance against health care expenditures, health care consumers are not exposed to the full expense associated with their health care decisions. Thus, in the presence of a reduced role for price, quality looms larger in consumer choice, and serves as an important rationing device. In the case of beneficiaries of the U.S. Medicare program, ${ }^{6}$ price is irrelevant for choice. Medicare pays hospitals and doctors fixed prices for their services, ${ }^{7}$ thus a Medicare beneficiary pays the same amount regardless of where she obtains service. Thus, for Medicare in particular, we would expect quality to be salient. ${ }^{8}$

This is not to say that price is not important. Most people with health insurance in the United States have some form of managed care insurance (Gabel et al., 2000). One of the defining features of managed care is restriction of consumer choice. Plan enrollees are allowed to choose from a pre-approved subset of

\footnotetext{
${ }^{4}$ See http: //www.ftc.gov/ and http://www.usdoj.gov/ for detailed information.

${ }^{5}$ Of course health care is not the only industry where effects on quality are important - it is, however, particularly salient here.

${ }^{6}$ Mostly those over age 65 , but also some disabled individuals, notably those with end-stage renal disease (kidney failure).

${ }^{7}$ Prices are regulated to be the same for a given service in a given location at a particular point in time. Regulated prices for a particular service vary by location and over time.
}

${ }^{8}$ This will also be true for in many European health systems. 
doctors and hospitals in their area - not all doctors or hospitals. Managed care plans thus bargain with doctors and hospitals over prices. Hospitals or doctors with prices that are too high will be excluded. In principle, managed care plans are acting as agents for consumers. Consumers want to reduce the price of care, since higher prices result in higher premiums and lower consumption of other goods.

However, quality is obviously important as well as price. Indeed, many health care analysts have identified quality problems as a major failing of the U.S. health care system (Kohn et al., 1999; Institute of Medicine, 2001). Antitrust is important for health care quality, since health care quality is determined via markets. ${ }^{9}$ The courts and the antitrust enforcement agencies have not dealt with quality in a uniform manner, however. In some antitrust cases, impacts on quality have been explicitly considered. In many cases, however, it has been simply presumed that price competition will lead to beneficial effects on quality. ${ }^{10}$

In this paper, I review the state of knowledge in economics on issues relevant to the assessment of the impact of competition in health care markets on quality. This is relevant for antitrust policy in the U.S., where there are well established health care markets, and for the evaluation of market oriented reform proposals in Europe and elsewhere. I limit myself to the economics literature, or papers published outside of traditional economics journals, but nonetheless using an economics approach. I do not survey the health services research literature on quality, in particular the literature on outcomes research. That literature is primarily concerned with measurement, as opposed to assessing the impact of competition. Romano (2003) provides an excellent review of this literature.

In what follows I first discuss performance stan-

\footnotetext{
${ }^{9}$ See Sage et al. (2003) for a discussion of the role of competition policy in determining health care quality.

${ }^{10}$ See Hammer and Sage (2002) for a comprehensive review of the treatment of health care quality by the courts in antitrust cases.
}

dards for competition, then review relevant findings from economic theory, then consider empirical evidence on health care competition and quality. The final section of the paper contains a summary and conclusions.

\section{Performance Standards}

In economics the performance standard is social welfare-consumer plus producer surplus. In some cases, however, the impacts on consumer and social welfare differ considerably. This is particularly relevant to the topic at hand. For example, it is possible that free entry of firms into a market can increase consumer welfare, but decrease social welfare. Suppose that entry leads to increased quality, but also that every firm pays a fixed cost of entry. Then the value consumers derive from the higher quality may be less than the increased costs due to entry. In this case consumer welfare is increased but social welfare is not. In what follows, I consider social welfare as the performance standard, but point out situations where considering only consumer welfare would lead to substantially different conclusions.

While it may seem uncontroversial to point out that there can be excessive quality in the context of an abstract model, it can be harder to think about this clearly in the context of health care. Quality in health care involves better or worse health, including death. As a consequence, a theoretical finding that quality is excessive can translate into a health care setting as stating that mortality rates are too low. Suggesting that social welfare would be improved by increasing mortality rates is not a pleasant prospect.

However, the same economic concepts apply here as to any other resource allocation problem. We want to devote resources to reducing patient mortality up until the point where the marginal benefit of reduced mortality is balanced by the marginal cost. This means that there will be a socially optimal mortality rate that will certainly be greater than zero. While this may seem repugnant, it is important to realize that there are competing uses for resources and if 
the value of reduction in patient mortality is not that great, then it may be better to devote those resources to finding a cure for cancer, school lunches, or battleships. It is also important to realize that tradeoffs involving mortality risks are made every day. We devote resources to improving traffic and airline safety, but not to the point that the risks of death associated with these activities are zero.

\section{What Do We Know From Economic Theory?}

Economists, antitrust scholars, and the courts intuitively think that competition is a good thing. Indeed, this is the presumption of antitrust law. Economic theory when there are differentiated products, however, is not so clear. ${ }^{11}$ In what follows, I review the state of knowledge on this issue from economic theory. I divide my review into analyses where price is regulated versus those where price is set by firms. These assumptions lead to very different results.

In particular, the impact of competition is reasonably clear when prices are regulated. If price is above marginal cost, competition leads to quality and consumer welfare being greater, although the impact on social welfare is ambiguous. If firms choose both price and quality, however, the results are much less clear.

\subsection{Models}

The theory of competition with differentiated products is complicated. My purpose here is not to review the literature, but to try and draw out key insights. As a consequence, I will use only simple presentations of the theory and not dwell on details. ${ }^{12}$ Product

\footnotetext{
${ }^{11}$ By differentiated products, I mean any products that consumers do not regard as identical, and thus are not perfectly substitutable. The products may be differentiated either because some are better (e.g., Honda vs. Yugo), or because they are somewhat different, at least to some consumers (e.g., Coke vs. Pepsi).

${ }^{12}$ For more complete presentations and reviews, see Tirole (1988); Eaton and Lipsey (1989); Anderson et al. (1992).
}

differentiation is represented in a number of different ways. In particular, economic models distinguish between vertical product differentiation, and horizontal product differentiation. With vertical differentiation, all consumers have the same preferences and thus agree that some products are better than others. I will refer to this as product quality. With horizontal differentiation, consumers can have differing preferences and thus some may like one product while others prefer another. I will call this product variety. Since the setup of the models differs, I will distinguish between them for clarity in reviewing results. There are also models with both product quality and product variety, which I discuss separately. Rather than going into detail on the differences, I will focus on what the models have to tell us about about the ability of markets to deliver products with the characteristics that people want (regardless of whether it is the right "quality" or right "variety").

In what follows I first review the literature on product differentiation where prices are set by firms in the market. I begin by covering models with product quality, then move on to those with product variety. I then cover the literature on product differentiation in markets with regulated prices. Last, I review the research that allows for both product quality and product variety. Table 2 presents a summary of the various papers and their findings.

\subsection{Prices Set by Firms}

There is a very broad literature on product differentiation. I will review only the findings from a few key articles. Most research has found ambiguous effects of competition (or monopoly) on welfare. In what follows, I review the key findings for product quality first, then for product variety.

\subsubsection{Product Quality}

First consider the model of product quality by Spence (1975). Here the question is whether a monopolist will produce the socially optimal level of quality (only one level of quality can be chosen). Let market in- 
verse demand be $p=P(q, z)$, where $p$ is price, $q$ is quantity, and $z$ is quality. Assume that price is decreasing in $q$ and increasing in $z$. Let the cost function be $T C=C(q, z)$, where costs are increasing in quantity and quality.

First consider the choices made by a social planner, who maximizes social welfare (the difference between consumer surplus and cost),

$$
\max _{q, z} W(q, z)=\int_{0}^{q} P(x, z) d x-C(q, z) .
$$

The first-order conditions to this problem are:

$$
\begin{array}{r}
P(q, z)-\frac{\partial C(\cdot)}{\partial q}=0 \\
\int_{0}^{q} \frac{\partial P(x, z)}{\partial z} d x-\frac{\partial C(\cdot)}{\partial z}=0 .
\end{array}
$$

Now consider the monopolist's problem. The monopolist maximizes profits,

$$
\max _{q, z} \pi=P(q, z) \cdot q-C(q, z) .
$$

The first-order conditions to the monopolist's problem are:

$$
\begin{array}{r}
P(q, z)+q \cdot \frac{\partial P(\cdot)}{\partial q}-\frac{\partial C(\cdot)}{\partial q}=0 \\
q \cdot \frac{\partial P(\cdot)}{\partial z}-\frac{\partial C(\cdot)}{\partial z}=0 .
\end{array}
$$

A comparison between the first-order conditions (3) and (6) is illuminating. Dividing the first terms in both equations by $q$, we have the social planner concerned with the average marginal valuation of quality,

$$
\left(\int_{0}^{q} \frac{\partial P(x, z)}{\partial z} d x\right) / q
$$

whereas the monopolist is concerned with the marginal marginal valuation of quality, the marginal consumer's marginal valuation of quality,

$$
\frac{\partial P(q, z)}{\partial z}
$$

The social planner considers the effect of an increase in quality on all consumers, whereas the monopolist considers only the effect of an increase in quality on the marginal consumer. Therefore, for a fixed quantity, the monopolist will provide too little, the right amount, or too much quality as,

$$
\left(\int_{0}^{q} \frac{\partial P(x, z)}{\partial z} d x\right) / q \gtreqless \frac{\partial P(q, z)}{\partial z} .
$$

The monopolist will supply the socially optimal quality only when the marginal consumer is the average consumer. When the marginal consumer's valuation is less than the average the monopolist will supply too little quality, and vice versa. Since it seems quite likely there is considerable heterogeneity in consumer preferences for health care quality, it seems particularly unlikely that the expression above is an equality.

The consequence is that there is no general theoretical prediction on whether monopoly reduces welfare when product differentiation takes the form of vertical quality differences. The exception to this conclusion occurs if the monopolist can perfectly price discriminate. Under this condition the monopolist will maximize social welfare. Since the monopolist captures all of consumer surplus when they perfectly price discriminate their problem is the same as the social planner's problem in (1). Although this will lead to the socially efficient outcome, there is redistribution away from consumers, since the discriminating monopolist captures all of the surplus.

It is possible to construct less general models that generate the conclusion that monopoly undersupplies or oversupplies quality. ${ }^{13}$ Consider the following ex-

\footnotetext{
${ }^{13}$ See Tirole (1988), Section 2.2.1 and Pepall et al. (2005), Section 7.5.1, for examples.
} 
ample from Pepall et al. (2005).

Let consumers have the following inverse demand function, $p=z(\theta-q)$. The term $\theta z$ is the reservation price, so consumers' reservation price is increasing in quality. Let the costs of production be constant and zero, but the costs of quality be described by $c=\alpha z^{2}$. Then the first-order profit maximization conditions for the monopolist are:

$$
\begin{aligned}
& \frac{\partial \pi}{\partial q}=z(\theta-2 q)=0 \\
& \frac{\partial \pi}{\partial z}=(\theta q-q)-2 \alpha z=0 .
\end{aligned}
$$

We can solve for the monopolist's profit maximizing quantity and quality, which are $q_{m}=\frac{\theta}{2}$ and $z_{m}=\frac{\theta^{2}}{8 \alpha}$.

The monopolist clearly does not choose the quantity and quality that maximize social welfare. Since the marginal cost of quantity is zero, the social welfare maximizing quantity is $\theta$. That is the quantity at which the demand curve crosses the horizontal axis. We can find the social welfare maximizing quality as follows. Social welfare is maximized where the change in consumer surplus from additional quality equals the marginal cost of quality,

$$
\begin{aligned}
\int_{0}^{q}(\theta-x) d x & =2 \alpha z \\
\theta q-\frac{q^{2}}{2} & =2 \alpha z .
\end{aligned}
$$

Solving, we find that the social welfare maximizing quality is $\frac{\theta^{2}}{4 \alpha}$.

This example precisely illustrates Spence's point. In this case, $\left(\int_{0}^{q} \frac{\partial P(x, z)}{\partial z} d x\right) / q=\theta-\frac{q}{2}$, and $\frac{\partial P(q, z)}{\partial z}=\theta-q$. So $\left(\int_{0}^{q} \frac{\partial P(x, z)}{\partial z} d x\right) / q>\frac{\partial P(q, z)}{\partial z}$, which means that the monopolist undersupplies quality.

Mussa and Rosen (1978) is an important paper with a different setup than Spence. In their paper,
Mussa and Rosen consider a monopolist that sells the same good at different levels of quality to discriminate among consumers with different valuations. ${ }^{14}$ The monopolist cannot perfectly price discriminate - it does not know individuals' valuations. The monopolist does know, however, the distribution of valuations in the population. As a consequence, the monopolist can set quality levels to get consumers to self-select their most preferred quality, thus allowing the monopolist to price discriminate. This leads to a distortion, thus monopoly leads to inefficient quality choice.

Consider a simple example with two types of consumers. Let type $1 \mathrm{~s}$ value quality more than type $2 \mathrm{~s}$. The monopolist can maximize profits by setting two levels of quality in such a way that the type 1s select the high quality good and the type 2 s select the low quality good.

In order to do this, the difference in quality between the high and low quality products has to be large enough that the type 1s will not choose the low quality good. The self-selection then allows the monopolist to set the prices of the high and low quality good to extract the maximum amount of surplus from consumers.

This, however, leads to a distortion. In order to get the type 1s to choose the high quality/high price product, the monopolist sets the quality on the low quality product low enough that it is not a good substitute to the type $1 \mathrm{~s}$. Thus quality choice is distorted.

As in all models of this type, the inefficiency results from an information asymmetry. If the monopolist knew consumers' valuations, then it could perfectly price discriminate. This would be socially efficient, although not desirable from consumers' perspectives.

Some further insight into the determinants of quality levels can be gained from the model of Dorfman and Steiner (1954). Their model is nominally about

\footnotetext{
${ }^{14}$ In Spence's model only one level of quality can be chosen. This drives the difference between Spence and Mussa and Rosen.
} 
choice of price and advertising, but can also be interpreted as about price and quality (although in a somewhat restrictive way). ${ }^{15}$ Consider a firm who has the following profit function, where per unit (and marginal) costs are constant in quantity $(q)$ and increasing in quality $(z)$, and $F$ represents fixed costs, ${ }^{16}$

$$
\pi=q(p, z) \cdot(p-c-d \cdot z)-F
$$

The first-order conditions with respect to price and quality are,

$$
\begin{aligned}
& \frac{\partial \pi}{\partial p}=q+p \cdot \frac{\partial q}{\partial p}-c-d \cdot z=0 \\
& \frac{\partial \pi}{\partial z}=p \cdot \frac{\partial q}{\partial z}-d \cdot q=0
\end{aligned}
$$

Let the price and quality elasticities of demand be

$$
\begin{aligned}
\varepsilon_{p} & \equiv-\frac{\partial q}{\partial p} \frac{p}{q} \\
\varepsilon_{z} & \equiv \frac{\partial q}{\partial z} \frac{z}{q}
\end{aligned}
$$

Then the first-order condition for price can be expressed in the following familiar form (remembering that marginal cost $=c+d \cdot z)$,

$$
p=\frac{c+d \cdot z}{1-\frac{1}{\varepsilon_{p}}}
$$

or as the Lerner Index,

$$
L=\frac{p-(c+d \cdot z)}{p}=\frac{1}{\varepsilon_{p}} .
$$

\footnotetext{
${ }^{15}$ Dorfman and Steiner model a monopolist's behavior. We can consider this an approximation to the behavior of a monopolistically competitive firm if we think of the demand function as a reduced form demand, e.g., an oligopolist's residual demand curve (see, e.g., Dranove and Satterthwaite, 2000).

${ }^{16}$ This is a modification of the cost structure used by Dorfman and Steiner.
}

After some manipulation we can obtain the following formula, known as the Dorfman-Steiner condition,

$$
\frac{d \cdot z}{p}=\frac{\varepsilon_{z}}{\varepsilon_{p}}
$$

or

$$
z=\frac{p}{d} \cdot \frac{\varepsilon_{z}}{\varepsilon_{p}} .
$$

This says that the amount spent on quality relative to sales should go up if the quality elasticity of demand increases or the price elasticity of demand declines, and vice versa. It also offers some other insights.

Presume that there exist "optimal" values of the price and quality elasticities, that is, there exist unique values which induce the monopolist to choose the socially optimal price and quality. Then if market power over price increases, i.e., $\varepsilon_{p}$ goes down, price will increase above the optimum. Quality will also increase, but to a supra-optimal level. ${ }^{17}$ Alternatively, if the quality elasticity decreases, quality will fall to a sub-optimal level, even if the price elasticity is at its optimal value. If an increase in market power reduces both the price and quality elasticities, the effect on quality is unclear. Price will certainly rise. If the price and quality elasticities fall by the same proportion, so that their ratio is unchanged, price will still rise and as a consequence quality will also rise above its optimal level. If the ratio of the quality elasticity to the price elasticity falls by more than price increases, quality will fall below the optimal level.

There are some other papers which provide a similar intuition, although the models are quite different from Dorfman and Steiner. Dranove and Satterthwaite (1992) consider the effects of information on price and quality when consumers are imperfectly informed about both. They find that if consumers have

\footnotetext{
${ }^{17}$ The excess profits may attract entry, but that entry is not necessarily welfare increasing. Each entrant adds $F$ to costs, but does not necessarily increase surplus accordingly. See the next section for an explicit discussion of this issue.
} 
better information about price than about quality, then this can lead to an equilibrium with suboptimal quality. Intuitively this is similar to an increase in the price elasticity of demand, with no increase in the quality elasticity.

Kranton (2003) examines the impact of competition on quality when consumers have imperfect information about quality. A number of papers have considered the question of whether there is an equilibrium at which the socially optimal quality is produced in a market where consumers are imperfectly informed about quality (but not about price) (Allen, 1984; Klein and Leffler, 1981; Shapiro, 1983). These papers demonstrate that there is an equilibrium with optimal quality if consumers can learn about quality ex post and if firms care enough about (future) repeat business. In this equilibrium there is a "qualityassuring price" that is above marginal cost and supports the optimal quality. Kranton shows that this result does not necessarily hold if firms compete in price for market share (a feature that is absent from the prior models). If a firm can increase (and sustain) its market share by cutting price, then there isn't an equilibrium at the socially optimal quality level. One may apply the intuition from the Dorfman and Steiner model to Kranton's result. The ability to increase market share via price cuts is analogous to the price elasticity of demand exceeding the quality elasticity, hence both price and quality are lower. If the reference point is an equilibrium with optimal quality, as in Kranton's model, then the lower quality is suboptimal.

Allard et al. (2005) explicitly consider competition in the physician services market. They consider a repeated game between physicians and patients. The patient's health is determined by observable medical care and physician effort. Physician effort is anything physicians do that affects patient health. It can be thought of as quality. The patient observes his health ex post, so physician effort is observable, but is non-contractible. In the static game physicians will supply sub-optimal effort. However, in the repeated game there is an equilibrium in which physicians supply optimal effort. This equilibrium obtains under certain conditions, in particular, if patient switching costs are not too high and there is an excess supply of physicians. If switching costs are high then effort will be suboptimal, but competition will result in effort levels above the minimum. ${ }^{18}$ Again, there are parallels to the Dorfman and Steiner intuition. In the Allard et al. model optimal effort occurs when patient switching costs are not too high. This is similar to the quality elasticity of demand being sufficiently high in the Dorfman and Steiner model. Sub-optimal effort occurs when switching costs are high, analogous to a low quality elasticity of demand.

While there are still no determinate conclusions from this framework, it does offer some useful guidance for thinking about issues of competition in health care markets. For example, the advent of managed care in the 1990s is commonly thought to have increased the price elasticity of demand facing health care firms (hospitals in particular). This should have led to decreased prices, and indeed seems to have done so. ${ }^{19}$ If there was no sufficiently countervailing increase in the quality elasticity, then quality should have fallen. It is important to bear in mind here that if the starting point was one where hospitals possessed market power, then the model predicts that quality should have been at supra-optimal levels. Thus a decrease in quality could be welfare improving (assuming it did not fall below the optimal level).

Another change in health care markets is the recent emphasis on medical errors and quality improvement. If that leads to the quality elasticity of demand increasing, then quality will increase. If the price elasticity remains unchanged this will increase price (since increased quality raises marginal cost), but price cost margins will remain unchanged. This framework will prove helpful in making sense of some results from the empirical literature, as we shall see later in this paper.

\footnotetext{
${ }^{18}$ In addition, if there is uncertainty in the relationship between patient health and physician actions, then physicians face some risk of patients switching even if they have supplied optimal effort. In this case there physicians will supply supraoptimal effort.

${ }^{19}$ See Dranove and Satterthwaite (2000) and Gaynor and Vogt (2000) for reviews of the evidence.
} 


\subsubsection{Product Variety}

In the previous section I reviewed the findings of economic theory on quality and competition for models of vertical product quality. I now turn to product variety. The classic references on this are Dixit and Stiglitz (1977) and Spence (1976).

To illustrate, consider a simple model based on Spence (1976) and Mankiw and Whinston (1986). Let consumer preferences be represented by:

$$
u=G\left(\sum_{i=1}^{\infty} f\left(q_{i}\right)\right)
$$

where firm $i$ produces output $q_{i}$ and both of the functions $G$ and $f$ are concave. This gives consumers a taste for product variety and also implies that the various firms' products are substitutes.

Costs consist of a fixed cost of entry, $F$, and variable cost, $c(q)$.

Impose symmetry for simplicity and let the social planner choose product variety (i.e., the number of firms, $N$ ),

$$
\max _{N} W(N)=G\left(N \cdot f\left(q_{N}\right)\right)-N \cdot c\left(q_{N}\right)-N \cdot F
$$

With $N$ firms the symmetric firm output is $q_{N}$.

Now consider profit maximizing behavior by firms. First note that with $N$ firms, utility maximization by consumers implies that the equilibrium price is $G^{\prime}\left(N \cdot f\left(q_{N}\right)\right) f^{\prime}\left(q_{N}\right)$. Each firm's equilibrium profits are therefore,

$$
\pi_{N}=G^{\prime}\left(N \cdot f\left(q_{N}\right)\right) f^{\prime}\left(q_{N}\right) \cdot q_{N}-c\left(q_{N}\right)-F .
$$

Now consider the first-order condition for the social planner,

$$
W^{\prime}=G^{\prime}\left[N f^{\prime} q_{N}^{\prime}\right]-c\left(q_{N}\right)-N c^{\prime}\left(q_{N}\right) q_{N}^{\prime}-F \text {. }
$$

We obtain the following expression by adding and subtracting the term $G^{\prime} f^{\prime} q_{N}^{\prime}$ and rearranging,

$$
W^{\prime}=\pi_{N}+N\left[G^{\prime} f^{\prime}-c^{\prime}\right] q_{N}^{\prime}+G^{\prime}\left[f-f^{\prime} q_{N}\right] .
$$

First, assume that the third term in the expression above is zero. Now consider the second term. $G^{\prime} f^{\prime}-c^{\prime}$ is price minus marginal cost. It is non-negative. The term $q_{N}^{\prime}$ is how per firm output changes with the number of firms. Assume it is negative, i.e. there is a business stealing effect of firm entry. Then, for any markup of price over marginal cost, the second term is negative. Thus $W^{\prime}<\pi_{N}$. This implies that $\pi_{N}$ at the socially optimal $N$ is positive. At a competitive (free entry) equilibrium, profits must equal zero. It is true that profits fall with the number of firms (see Mankiw and Whinston). This then implies that the number of firms in competitive equilibrium is greater than the socially optimal number, i.e. competition produces too much product diversity. This happens because firms do not take the business stealing effect into account. The gain in social welfare from entry is outweighed by the fixed costs incurred. The conclusion is different, however, when measured against a consumer welfare performance standard. Ignoring the fixed costs incurred by entering firms, since they don't affect consumer welfare, implies that consumers are made (weakly) better off by entry. ${ }^{20}$

Now assume that the second term in (23) is zero and consider only the third term. $G^{\prime}\left[f-f^{\prime} q_{N}\right]$ represents the effect of product diversity (due to more firms). This term is positive, since $f$ is concave. Consumers value product diversity, but an entering firm cannot capture all of the increase in surplus they generate. $G^{\prime} f$ is the contribution to surplus of another firm, and $G^{\prime} f^{\prime} q_{N}$ is the firm's revenue. Using the argument from the preceding paragraph, the fact that this term is positive implies that a free entry equilibrium will produce too little product diversity, due to the non-appropriability of social surplus.

\footnotetext{
${ }^{20}$ If there is $100 \%$ business stealing then consumer welfare is unaffected. If there is less than $100 \%$ business stealing, then consumers are made better off.
} 
It isn't possible in general to tell whether one of these terms is larger than the other. The business stealing effect could dominate the nonappropriability effect, or vice versa, or they could be exactly balanced. Therefore a free entry monopolistically competitive equilibrium can result in too much product diversity, too little, or precisely the optimal amount.

\subsection{Regulated Prices}

In contrast to the mostly ambiguous theoretical results on competition and quality with variable prices, the theoretical literature on competition and quality when prices are regulated is clear. When price is above marginal cost, competition leads to more quality. This improves consumer welfare, but can have any impact on social welfare. In particular, there is a distinct possibility that competition will lead to excessive quality provision from the perspective of social welfare. In this section the focus is solely on product quality, since it is well known that firms will pursue minimal product variety in the absence of price competition (e.g., Hotelling, 1929; White, 1972; Tirole, 1988, section 7.1.3). In what follows, I review the general economics literature on this topic and also that from health economics.

Government regulation commonly leads to fixed prices. The most prominent example of this in U.S. health care is the Medicare program. Price regulation in health care is the norm in most other countries. Medicare sets fixed prices for hospitals based on a patient's diagnosis. ${ }^{21}$ Doctors are paid fixed prices for services provided. Further, Medicare benefits are such that Medicare beneficiaries pay the same amount regardless of the provider they use to obtain care. As a consequence, economic models of competition with regulated prices are relevant here.

These models largely derive from analyses of industries subject to price regulation up until the 1970s

\footnotetext{
${ }^{21}$ Prices are fixed for a given location and point in time. Thus Medicare regulated prices vary geographically and intertemporally. This applies to both doctors and hospitals.
}

and 1980s, e.g., airlines and taxis. ${ }^{22}$ There are also some models specific to health care. ${ }^{23}$ The intuition of these models is as follows. Price is regulated, so firms compete for consumers on non-price dimensions, i.e. "quality." If the regulated price is set above marginal cost at some baseline level of quality, then firms will increase quality to try to gain market share. This will continue until profits are zero. Since firms don't take account of stealing market share, in equilibrium quality levels can be excessive.

Consider the following sketch of a simple model. Let quality have only a vertical dimension, i.e., "more is better." For simplicity in exposition, assume that the demand that any firm $i$ faces is separable in its market share, $s_{i}$, and the level of market demand, $D$. Firm $i$ thus faces a demand of:

$$
q_{i}=s_{i}\left(z_{i}, \mathbf{z}_{-\mathbf{i}}\right) D\left(\bar{p}, z_{i}, \mathbf{z}_{-\mathbf{i}}\right)
$$

where $s_{i}$ is firm $i$ 's market share, $z_{i}$ is firm $i$ 's quality, $\mathbf{z}_{-\mathbf{i}}$ is a vector of all other firms' qualities, $D$ is market demand, and $\bar{p}$ is the regulated price. ${ }^{24}$ Assume that $i$ 's market share is increasing in own quality, decreasing in the number of firms, and that the responsiveness of market share to own quality is also increasing in the number of firms.

Assume that firms all use the same technology and face the same input prices. Then they each have costs described by:

$$
c_{i}=c\left(q_{i}, z_{i}\right)-F
$$

where $c(\cdot)$ is variable cost, and $F$ is a fixed cost of entry.

${ }^{22}$ See, for example, Douglas and Miller (1974); Schmalensee (1977); Vander Weide and Zalkind (1981); White (1972) on airlines and Frankena and Pautler (1984) on taxicabs.

${ }^{23}$ Allen and Gertler (1991); Held and Pauly (1983); Pope (1989).

${ }^{24}$ Note that for consumers insulated from the cost of consumption, as in health care, the price they face will be less than the price received by the firm. I ignore this in order to keep this sketch of a model simple. It would not affect the conclusions in any event. 
Further assume that there is free entry and exit, so that all firms earn zero profits in equilibrium. Then, assuming Nash behavior, equilibrium is described by the solutions to the following across all firms $i$ :

$$
\begin{aligned}
\frac{\partial \pi_{i}}{\partial z_{i}}= & {\left[\bar{p}-\frac{\partial c_{i}}{\partial q_{i}}\right]\left\{\frac{\partial s_{i}}{\partial z_{i}} D(\cdot)+s_{i} \frac{\partial D(\cdot)}{\partial z_{i}}\right\} } \\
& -\frac{\partial c_{i}}{\partial z_{i}}=0 .
\end{aligned}
$$

and

$$
\pi_{i}=\bar{p} \cdot q_{i}-c_{i}=0
$$

Inspection of (26) yields some immediate insights. First compare equilibrium quality under monopoly to that with multiple firms. Notice that, since a monopolist faces market demand, the first term in curly brackets in (26) vanishes and $s_{i}=1$. Since $\frac{\partial s_{i}}{\partial z_{i}}$ is positive (by assumption), the term in curly brackets is larger with multiple firms than with a monopolist, so equilibrium quality is higher with competition. Whether welfare is higher depends on the relative magnitudes of $\frac{\partial s_{i}}{\partial z_{i}}$ and $\frac{\partial D}{\partial z_{i}}$. In particular, if $\frac{\partial D}{\partial z_{i}}$ equals zero, then increases in quality do not shift market demand, and quality competition is simply over market share, and hence wasteful.

Since $\frac{\partial s_{i}}{\partial z_{i}}$ increases with the number of firms (i.e., the firm's demand becomes more elastic with respect to own quality the more alternatives there are for consumers), quality competition will be more intense with entry and equilibrium quality will increase with the number of firms in the market. This benefits consumers, but may not increase social welfare. In particular, the increase in consumer surplus from increased quality may be outweighed by the increased costs, particularly if there is diminishing marginal utility from quality and diminishing returns in quality production. As indicated previously, this may result in excessive quality levels.

The positive predictions of this model are clear. Quality is increasing in the number of firms in the market, i.e., competition leads to more quality. Further, quality is increasing in the regulated price. One may write down a firm's equilibrium quality function as the (implicit) solution to equations (26) and (27),

$$
z^{e}=z\left(\bar{p}, c_{q}, c_{z}, s_{i}, D\right)
$$

where $c_{q}$ and $c_{z}$ denote first derivatives. The firm's level of quality depends on the level of the regulated price, the marginal cost of quantity, the marginal cost of quality, the level of demand, market share, and the quality elasticities of market share and market demand. This can be seen informally by manipulating (26) to obtain the following expression,

$$
z=\frac{\left(\bar{p}-c_{q}\right)\left[\eta_{z}^{s}+\eta_{z}^{D}\right]\left(s_{i} \cdot D\right)}{c_{z}}
$$

where $\eta_{z}^{s}$ and $\eta_{z}^{D}$ are the quality elasticities of market share and market demand, respectively. Quality is increasing in price, the elasticity of demand with respect to quality, and the firm's total demand. Quality is decreasing in the marginal costs of quantity or quality.

This has implications for econometric specifications for empirical analysis. The equation to be estimated is (28). However, measures of marginal cost, market share, and demand are likely to be endogenous in an econometric equation. One would employ exogenous determinants of these factors, such as cost shifters $(W)$, demand shifters $\left(X_{D}\right)$, and the number of firms $(N)$. A reduced form econometric specification would thus look something like the following,

$$
z^{e}=\mathcal{Z}\left(\bar{p}, W, X_{D}, N, \varepsilon\right)
$$

where $\varepsilon$ is a random error term.

As we shall see, most of the empirical studies to date include a measure of market structure and a number of control variables. They are not generally clear about whether the control variables represent cost shifters or demand shifters. Further, the reg- 
ulated price, $\bar{p}$, is generally omitted from empirical studies, although theory indicates its inclusion.

The normative implications of the model are less clear than the positive ones. Depending on the nature of demand (specifically how responsive market demand is to quality), competition may lead to excessive quality provision. Similarly, a higher regulated price may reduce welfare by leading to excessive quality. These conclusions, however, are altered if we consider only consumer welfare. Consumers are never made worse off by competition. If competition leads only to demand stealing they are no better off as a result, but if it leads to any increase in market demand then consumers are unequivocally better off.

The model outlined above is not specific to health care. In particular, the majority of firms in the hospital industry are not-for-profit. Let us now write down a simple model that captures this aspect of the health care industry. There have been many models of not-for-profit hospitals (Pauly and Redisch, 1973; Newhouse, 1970; Lee, 1971; Lakdawalla and Philipson, 1998). While there is no agreement on a general model, most models posit an objective function which includes profits and some other argument, such as quantity or quality. Therefore, let us assume that not-for-profit hospitals have an objective function which includes quality and profits (as a shorthand for everything else they care about). Further, for simplicity, let this function be additively separable in quality and profits and linear in profits:

$$
U_{i}=u\left(z_{i}, \pi_{i}\right)=v\left(z_{i}\right)+\pi_{i}
$$

We can now revisit the first-order conditions for quality choice (26), modified to take account of this objective function:

$$
\begin{aligned}
\frac{\partial U_{i}}{\partial z_{i}}= & {\left[\bar{p}-\frac{\partial c_{i}}{\partial q_{i}}\right]\left\{\frac{\partial s_{i}}{\partial z_{i}} D(\cdot)+s_{i} \frac{\partial D(\cdot)}{\partial z_{i}}\right\} } \\
& -\frac{\partial c_{i}}{\partial z_{i}}+\frac{\partial v}{\partial z_{i}}=0 .
\end{aligned}
$$

Notice that the only difference with the first-order conditions for an industry of profit maximizing firms is the presence of the last term, $\frac{\partial v}{\partial z_{i}}$. Since this term is positive, the value that not-for-profit firms put on quality acts like a reduction in the marginal cost of producing quality, i.e., not-for-profit firms will act like for-profit firms with a lower marginal cost of quality. ${ }^{25}$ This implies that quality will be higher in equilibrium. The comparative statics, however, are identical with an industry of profit maximizing firms. Quality is increasing in the number of firms and the regulated price, as before.

\subsection{Models with both Product Quality and Variety}

There are some models with both product quality and variety. Product variety in these models is usually chosen first, and is typically location along a line. Product quality then consists of choice of a level of a common characteristic. These are sequential games, with strategic variables determined in order. The sequential nature of these games is necessary for tractability, but also leads to different outcomes than if the strategic variables are chosen simultaneously. Both price setting and regulated price situations are considered.

Kamien and Vincent (1991) and Ma and Burgess (1993) are two similar papers. The models are of duopolies with fixed locations where firms go on to sequentially choose quality and price. Variety is determined first (exogenously), then firms either choose quality and price simultaneously or then quality and last price. These papers both give the result that unregulated competition leads to suboptimal quality when price is chosen after quality. Fierce competition in the anticipated subgame in prices that follows the quality choice subgame leads firms to choose lower quality, since the tough price competition lowers the return to quality. This turns out to be suboptimal, thus price regulation can thus improve on competition.

\footnotetext{
${ }^{25}$ This is the same specification and result as for not-forprofit firms that care about quantity, as opposed to quality. See Lakdawalla and Philipson (1998); Gaynor and Vogt (2003).
} 
Kamien and Vincent (1991) show that with unregulated competition there is a symmetric equilibrium in which quality is too low, due to the fierce price competition that ensues. They also show that price regulation can lead to the optimal quality level if the price is set just right. If not, quality can be too high or too low.

Ma and Burgess (1993) also consider a model where firms have fixed locations. Firms then choose quality and price sequentially. If there is a fixed cost of quality then firms react to quality disadvantages by price reductions. This price response reduces the return to higher quality. As a consequence, firms have an incentive to provide less quality and thus provide a suboptimal level of quality to avoid generating tough price competition. They find that price regulation can improve welfare by eliminating the quality distortion induced by price competition.

These results derive from a number of specific assumptions of the model. Ma and Burgess show that if firms compete simultaneously in quality and prices, instead of sequentially, equilibrium qualities are optimal. If there are only marginal costs of quality and no fixed costs, then the equilibrium quality is optimal. The assumption of linear demand eliminates the Spence effect (difference between average and marginal valuation). Nevertheless, Ma and Burgess show that there are conditions under which competition leads to suboptimal quality.

A paper by Lyon (1999) adapts this kind of model to the institutional specifics of health care markets. Specifically, Lyon examines a model of health care competition which includes insurers and hospitals. The insurance market is presumed competitive. Hospitals are differentiated both with regard to product variety and quality. Product variety is captured as location and product quality is the quality of care. Product variety is fixed (the hospitals are at the ends of a unit line). Lyon assumes the entire market is covered, so competition is only over market share. He considers two kinds of insurance: "traditional" insurance in which consumers have free choice of hospitals, and managed care, in which choice is restricted.

Lyon shows for traditional insurance that hospitals will increase prices to the point where the last consumer is just indifferent about purchasing insurance. Since all consumers are insured, only a fraction of any one hospital's price increase is passed on to consumers through the insurance premium. This softens price competition, and thus hospitals compete on quality. Since the competition is only over market share, in equilibrium quality levels are excessive and prices are supra-optimal.

The results for managed care are quite different. Under managed care, there are exclusive contracts between hospitals and insurers, thus the choice of an insurer is the same as choice of a hospital. In this case, a price increase by a hospital is fully passed on through the insurance premium. This makes price competition tougher than in the traditional insurance case, and thus prices are lower. Quality is therefore lower than in the traditional insurance case. Quality can be is lower or higher than the social optimum, depending on whether it is sufficiently costly. Nonetheless, consumers are always better off with managed care than with traditional insurance. Managed care provides lower quality, but also lower prices, and lower prices are low enough to more than compensate for the lower quality.

Nuscheler (2003) studies competition with regulated prices. He models competition as a three stage game. In the first stage, firms enter, in the second stage they choose location (on a circle), and in the third stage they choose quality. Quality is increasing in the regulated price. Entry is decreasing in the regulated price, since potential entrants anticipate fiercer quality competition at a higher price.

Not too surprisingly, (first-best) optimality cannot be achieved when price is the only instrument available to the regulator. The regulator would like to achieve optimal entry and quality (location is symmetric in equilibrium, so that is determined by entry), but that will not generally be feasible with only one policy instrument. If the regulator sets the price at the level that induces optimal quality, there is excessive entry. If the regulator sets the price at the level that leads to optimal entry, then there is excessive quality. This could be solved either by a nonlin- 
ear price, or by regulating entry as well as price.

Barring those possibilities, if the regulator can commit to a fixed price at the very beginning of the game (with no re-optimization in subsequent stages), then there is a second-best regulated price. Equilibrium entry and quality at this price will both exceed the optimal (first-best) levels. Nuscheler shows, however, that this second-best price is not credible. The regulator's optimal price changes after the second stage of the game (location, following entry in stage 1$)$. This is therefore the only credible price by the regulator. This price leads to the first-best quality, but induces excessive entry.

The results from these papers reinforce the findings reviewed in the preceding sections that competition need not lead to optimal quality. The papers by Kamien and Vincent and $\mathrm{Ma}$ and Burgess predict that when prices are set by firms, competition will lead to decreased, and suboptimal, quality. Lyon also models competition with prices set by firms, but obtains different results from Kamien and Vincent and $\mathrm{Ma}$ and Burgess, due to the presence of health insurance in his model. Lyon's results depend on the nature of the health insurance regime. If consumers have insurance contracts that allow them choices over hospitals, then competition leads to increased, and excessive quality. If consumers have contracts that restrict their choice of hospital, then competition can lead to too little or too much quality. Nuscheler shows that quality is increasing in the regulated price. The regulator may set the price to achieve optimal quality, but cannot also achieve the optimal market structure.

\section{What Do We Know From Econo- metric Studies?}

There is a rapidly growing empirical literature on competition and quality in health care. At present the evidence from this literature is entirely on hospital markets. In what follows I will review this litera- ture, focusing mainly on the economics literature. ${ }^{26} \mathrm{I}$ will first review the results from econometric studies of markets with regulated prices, and then variable prices, reversing the ordering of the preceding theory section. I do this because the theoretical predictions for markets with regulated prices are clearer, thus they offer a clearer target for econometric hypothesis testing.

The studies reviewed here employ a variety of econometric approaches. The modal approach is what I will call a "Structure-Conduct-Performance" (SCP) specification. These econometric models are derived from a conceptual model that hypothesizes a causal link from market structure to firm conduct and then to industry performance. ${ }^{27}$ Most SCP models applied to health care focus on the link between market structure and firm conduct, and omit industry performance. The typical conduct measure in the general industrial organization literature is price or price-cost margin. The typical measure of market structure is the Herfindahl-Hirschmann Index (HHI), which is the sum of the squares of all firms' market shares. $^{28}$ The equation usually estimated has roughly the following appearance,

$$
p=\beta_{0}+\beta_{1} q+\beta_{2} X_{D}+\beta_{3} W+\beta_{4} H H I+\varepsilon
$$

where $X_{D}$ represents demand shifters and $W$ captures cost shifters. The SCP studies of quality simply employ a measure of quality as the dependent variable in this equation, rather than price. Only one of the studies I review estimated equations for price and quality together.

The SCP approach has a number of well recognized problems when price is the dependent variable

\footnotetext{
${ }^{26}$ Not too surprisingly, this captures the vast majority of such studies, given the nature of the topic. While I believe I have captured most of the prominent work on this topic, I do not claim to have covered every study, however, in particular any that may have appeared in the medical literature.

${ }^{27}$ See Carlton and Perloff (2005).

${ }^{28}$ I.e, HHI $=\sum_{i=1}^{N} s_{i}^{2}$, where $s_{i}$ is firm $i$ 's market share, and
} there are $N$ firms in the market. 
(see Bresnahan, 1989; Schmalensee, 1989, on these issues). These problems also apply when quality is the dependent variable, and there are some additional issues. First, the use of the HHI in a pricing equation can be explicitly derived only from a homogeneous goods Cournot model of conduct. ${ }^{29}$ Obviously an SCP regression with quality as the dependent variable does not derive from this framework. In the case of regulated price, theory does point to an econometric model with a measure of market structure on the right hand side (see equation (30)). Even in this case, or even if one thinks of a quality SCP regression as deriving from a broad conceptual framework as opposed to a specific theoretical model, a number of issues remain. The HHI (or any market structure measure) is usually regarded as endogenous. Unmeasured variation in demand and cost factors affect both quality and market structure. For example, a firm with low costs is likely to have both a high market share (leading to a high HHI) and choose high quality (refer to equation (18) for optimal quality in the Dorfman and Steiner type framework or equation (29) for optimal quality for a regulated price regime).

Two additional specification issues arises in regard to SCP studies of markets with regulated prices. When firms set prices it is clear that price and quality are determined simultaneously, so an SCP model might either include price and treat it as endogenous, or simply include exogenous determinants of price. Typically price is not included in the studies reviewed here, although it is not clear whether the authors were explicitly trying to include exogenous determinants of price. When price is regulated, however, price (or the price cost margin) should appear as an exogenous determinant of quality (again, see equation $(30))$. In some studies price is omitted based on the argument that, since price is regulated, price does not affect demand (e.g., for Medicare beneficiaries). The regulated price should be included, however, because it is a determinant of supply, not demand.

\footnotetext{
${ }^{29}$ In that case, the coefficient on the HHI in an SCP regression captures the elasticity of demand, not firm conduct (which is already assumed to be Cournot).
}

There is another complication due to the nature of hospitals. The major purchasers of hospital services are Medicare and private health insurers. Medicare sets regulated prices. Prices from private health insurers are determined in the market. Since hospitals generally sell in both markets, one must either account for this or presume that there are no complementarities between the two (e.g., demand and cost are completely separable in Medicare and private output). Many of the studies that focus on Medicare seemingly make the implicit assumption of separability.

While the majority of the studies I review here employ an SCP framework, some employ different approaches. Some studies evaluate the impact of mergers, some evaluate the impact of regulatory changes (e.g, price deregulation), two studies estimate demand, one study examines the determinants of the number of firms, and a number estimate the relationship between hospital volume of a surgical procedure and patient health outcomes. Each of these approaches have their advantages and disadvantages. I will discuss these in the context of evaluating the various studies.

Before proceeding, however, I want to note that the results of the majority of these studies provide evidence only on positive questions, e.g., "Does competition increase quality?". Few of these studies allow for normative analysis. This first wave of studies consists for the most part of policy evaluation and reduced form studies. ${ }^{30}$ It is not possible to evaluate effects on welfare with these kinds of studies. This should not be taken as a criticism of these studies, but simply a recognition of what sorts of inferences can be drawn from them.

\footnotetext{
${ }^{30}$ By policy evaluation studies, I mean econometric specifications that evaluate the impact of some policy or (economic) environmental factor, but are not derived from an explicit economic model. By reduced form, I mean an econometric specification that is the reduced form of a specific economic model.
} 


\subsection{Studies with Regulated Prices}

There are a number of studies of hospital quality provided to Medicare patients. The amount a Medicare beneficiary pays is the same, regardless of where she obtains care (again, in a given area at a given point in time). As a consequence, price is not a strategic variable for hospitals serving Medicare patients. Table 3 presents a summary of these studies and their findings. The entry in the column labelled "Effect of Competition on Quality" indicates the direction of the relationship between the competition measure and the quality measure. For example, in the first row, the entry "Increase" in that column indicates that the quality is higher in more competitive markets. For the study cited in the first row (Kessler and McClellan, 2000), quality is measured by mortality and competition is measured by the HHI. Quality is inversely related to mortality - lower mortality is higher quality. Competition is inversely related to the $\mathrm{HHI}$ - the HHI is lower in more competitive markets. So, the finding that competition increases quality is based on a positive empirical relationship between mortality and the HHI - mortality is higher in less competitive markets.

Kessler and McClellan (2000) is a study of the impact of hospital market concentration on riskadjusted one year mortality from acute myocardial infarction (AMI, i.e., a heart attack) for Medicare patients. Expenditures on these patients are also studied. The study included data on all non-rural Medicare beneficiaries with AMI during selected years from 1985 to 1994. Kessler and McClellan use the SCP framework discussed above, with some modifications. They instrument for the HHI with hospital market shares predicted from a model of patient choice of hospital, where patient choice is largely determined by distance from the hospital. They also employ zip code fixed effects. As a consequence, the effects of hospital market concentration are identified by changes in the predicted HHI. The specification they employ, however, omits the regulated Medicare price. A number of hospital and area characteristics are included, HMO enrollment among them. It is unclear whether they are considered demand or cost shifters.

The results from this study are striking. Kessler and McClellan find that risk-adjusted one year mortality for Medicare AMI patients is significantly higher in more concentrated markets. In particular, patients in the most concentrated markets had mortality probabilities 1.46 points higher than those in the least concentrated markets (this constitutes a 4.4 percent difference) as of 1991. This is an extremely large difference - it amounts to over 2,000 fewer (statistical) deaths in the least concentrated vs. most concentrated markets. The results with regard to expenditures have a somewhat different pattern. Prior to 1991, expenditures were higher in less concentrated markets, while the reverse is true as of 1991.

Kessler and McClellan also find that HMO enrollment reduced expenditures on average, but had no statistically detectable impact on mortality. They also find an interaction effect between HMO enrollment and market concentration. In low HMO enrollment states, patients in less concentrated markets had higher expenditures and better (although statistically insignificant) outcomes. In states with high HMO enrollment, patients in less concentrated markets had lower expenditures and lower mortality.

The positive inferences from this study are clear. Mortality from heart attacks for Medicare patients is lower in less concentrated markets. The effects of concentration are stronger beginning in 1991 and are reinforced by HMO enrollment. The omission of the regulated price is unfortunate, although for this omission to lead to biased estimates the changes in the omitted price would have to be correlated with the within zip code changes in the predicted HHI. It is unclear whether the inclusion of market and hospital characteristics is intended to control for possible hospital complementarities between Medicare and private output. So long as it is unlikely there are important omitted factors there should be no problem with bias. While it is clear that concentration affects hospital quality, the mechanism by which this works is not.

It seems unlikely that hospitals deliberately choose lower quality in the form of an increased probability 
of death. What may be happening is that hospitals in more concentrated markets take some of their excess profits in slack. General slack in the hospital may have the unintended consequence of higher mortality. Another issue with regard to this application is whether hospitals compete for heart attack patients. Tay (2003) states that one-half of heart attack patients arrive at the hospital via ambulance. It seems unlikely that these patients have any choice of hospital, hence hospitals cannot compete for these patients. I think the most likely story is that heart attack patients are the "canary in the mine shaft." Hospitals in more competitive environments are pressured to be better across the board, and that manifests itself clearly in a very sensitive area - heart attack patient mortality.

While the basic positive results from this study are clear, I do not believe that there are clear normative inferences. The results show that both expenditures and mortality are lower in less concentrated markets. Kessler and McClellan claim that this implies there is a welfare gain from competition. I do not believe this is so. First, the measure of Medicare expenditures they use is not a measure of economic cost. Second, and more fundamentally, economic theory does not predict that quality competition in price regulated markets will lead to socially optimal quality levels. If price is above marginal cost at the optimal quality then competition can lead to excessive quality. Consumer welfare may be enhanced, but can be outweighed by reduced producer welfare. In essence, the benefits that accrue to consumers from increased quality can be smaller than the costs incurred. Therefore, the finding that quality is higher in less concentrated markets tells us that consumers are likely better off, but does not tell us if social welfare has been improved. This is a question which an SCP analysis is not designed to answer. Quality in unconcentrated markets could be too high, too low, or just right. The model that Kessler and McClellan employ ably identifies the relation between concentration and quality, but does not allow for the evaluation of welfare effects.

As I stated when discussing performance standards, we want to devote resources to reducing pa- tient mortality up until the point where the marginal benefit of reduced mortality is balanced by the marginal cost. This means that there will be a socially optimal mortality rate that will certainly be greater than zero, and it is possible to devote too many resources to reducing mortality. While reduced mortality is a good thing, it is not without cost, therefore we cannot conclude that social welfare is improved simply based on evidence that competition leads to reduced mortality.

Gowrisankaran and Town (2003) estimate the effects of hospital market concentration on riskadjusted mortality rates for AMI and pneumonia, for both Medicare and HMO patients. I will discuss their findings with regard to Medicare patients here, since the price is regulated for them, and discuss the findings with respect to HMO patients in the next section. Gowrisankaran and Town use data from Los Angeles county from 1991-1993 for AMI and 19891992 for pneumonia. Their approach is similar to that of Kessler and McClellan. They use an SCP framework, instrumenting for the HHI with hospital market shares predicted from a patient choice equation, where distance is the main determinant of hospital choice. An innovation is that they construct separate, hospital-specific, HHIs based on (predicted) hospital market shares for Medicare, HMO, Medicaid, indigent and self-pay patients, and indemnity patients.

Gowrisankaran and Town find, in contrast to Kessler and McClellan, that mortality is worse for Medicare patients treated in hospitals with lower Medicare HHIs. The implication is that competition reduces quality for Medicare patients. Gowrisankaran and Town hypothesize that Medicare margins are small or negative, or that hospitals may deviate from profit-maximizing behavior. If Medicare margins are indeed negative (i.e., $p<M C$ ), then the results are consistent with theory. It seems unlikely, however, that this is true for AMI. Heart treatments for Medicare patients are widely thought to be profitable. Indeed, there is substantial entry of hospitals specializing only in the treatment of heart disease. Since Medicare patients are a substantial portion of heart patients, it seems as if Medicare margins must be significant in order to generate the observed entry. 
Small or negative Medicare margins for pneumonia, however, do seem plausible. We do not observe the entry of hospitals specializing in pneumonia, or pulmonary disorders generally.

This study also omits Medicare price. Since Gowrisankaran and Town only examine Los Angeles county there may be little or no variation in Medicare price across hospitals for a given year. Although there should be temporal variation, they have only a short time period. As a consequence, there may not be enough variation in their sample to estimate a parameter for Medicare price. It includes some hospital characteristics, although it is unclear if these characteristics are considered demand or cost shifters.

It is hard to know why the results of this study contrast so markedly with the previous one. It may be that the Medicare price is below marginal cost (on average) for the hospitals in Gowrisankaran and Town's study, while the opposite is true for the hospitals in Kessler and McClellan's study. Since neither study included Medicare price it is impossible to evaluate this hypothesis. It is also possible that the estimated relationship between the HHI and mortality is sensitive to the choice of instruments. Gowrisankaran and Town and Kessler and McClellan use similar, but not identical, instrumenting strategies. Obviously identification is driven by the instruments, so it is possible that the differences in instruments are driving the differences between the studies. This is only speculation, however. The opposite results from the two studies suggest caution in drawing strong conclusions about the impact of market structure on hospital mortality at this point.

Kessler and Geppert (2005) extend the framework employed by Kessler and McClellan to consider the impact of concentration on differences in quality between patients. Their work is inspired by the theoretical result that oligopolists will find it optimal to engage in product differentiation in order to relax price competition (see Tirole, 1988, section 7.5.1). These theory papers are not directly relevant for Kessler and Geppert's empirical exercise, since the theory examines quality dispersion when firms set prices. Kessler and Geppert examine Medicare patients, for whom price is set via regulation. Clearly any incentive to engage in product differentation is not related to a desire to relax price competition for Medicare patients. It is possible that hospitals may be attempting to relax price competition for private patients, and are unable to quality discriminate between Medicare and private patients, perhaps for legal or ethical reasons. It seems like it should be a straightforward result from models where firms choose both product variety and product quality that oligopolists operating in a market with a regulated price have an incentive to differentiate themselves with regard to product variety in order to avoid the kind of quality competition described previously in Section 3.3. ${ }^{31}$

Kessler and Geppert examine outcomes (readmissions, mortality) and expense (expenditures, various measures of utilization) for Medicare heart attack patients, as in Kessler and McClellan. They contrast outcomes and expenditures for high-risk and low-risk patients in highly concentrated vs. unconcentrated markets. High-risk patients are those who were hospitalized with a heart attack in the previous year, whereas low-risk patients had no such hospitalization. They find that low-risk patients receive more intensive treatment in highly concentrated markets, but have no statistically significant difference in outcomes. High-risk patients, on the other hand, receive less intensive treatment in highly concentrated markets, and have significantly worse outcomes. They conclude that competition leads to increased variation in patient expenditures, and that it is welfare enhancing, since on net outcomes are better and expenditures are lower. Medicare price is omitted, as in previous studies.

\footnotetext{
${ }^{31}$ If one takes the kind of model used in Lyon (1999) or Kamien and Vincent (1991), where firms locate on a line, it seems evident that firms will have an incentive to locate as far apart from each other as possible (at the ends of the line), rather than nearby (in the middle). If they locate in the middle, the firms are identical, so the one that produces the highest product quality will take the entire market. Thus firms will engage in fierce product quality competition, up until the point that profits are dissipated. If firms are located at the ends of the line, then each firm will be considerably more attractive to consumers located very close to it. This will dampen quality competition.
} 
This paper adds to the evidence that concentration is significantly correlated with readily observable measures of quality for hospitals. As I stated previously in discussing Kessler and McClellan, I do not believe that there are clear welfare implications. The statistical relationship between quality dispersion and concentration is surprising and interesting. So far as I know, this is the only paper to examine quality dispersion. What economic behavior generated these patterns in the data is an intriguing puzzle.

Mukamel et al. (2001) examine risk-adjusted hospital mortality for Medicare patients in 134 Metropolitan Statistical Areas (MSAs) in 1990. They focus on the impact of HMOs, but also examine hospital market concentration. Mukamel et al. (2001) find that HMO penetration (the percent of the MSA population enrolled in an HMO) has a negative impact on excess hospital mortality (the difference between observed mortality and predicted risk-adjusted mortality), i.e., HMO penetration is associated with better quality. Hospital market concentration (measured by the HHI) has no statistically significant impact on mortality. HMO market concentration is also included as an explanatory variable, although it is not significant. Medicare price is omitted. It is unclear what to make of these results. First, Mukamel et al.'s specification includes inpatient expenditures, which are certainly endogenous, as well as hospital HHI, HMO HHI, and HMO penetration, which may very well be endogenous, so it is unclear that the resulting estimates are consistent. It is possible that hospital concentration does truly have an impact on mortality, but that it is not consistently estimated in this study. Second, it is not clear how enrollment in private $\mathrm{HMO}$ plans affects the mortality of Medicare patients. Presumably there has to be some spillover effect, but the nature of the mechanism is unclear, as Mukamel et al. acknowledge.

A recent study that does take account of Medicare price effects is Shen (2003). Shen examines the impact of financial pressure from reduced Medicare payments and HMO penetration on mortality from AMI, controlling for the hospital's competitive envi- ronment. ${ }^{32}$ She examines data from 1985-1990 and 1990-1994 for most nonrural hospitals in the U.S. Shen's measure of market structure is an indicator for whether there are five or more other hospitals within a 15 mile radius of a hospital. This is interacted with a measure of the change in the Medicare price and the change in HMO penetration. There are direct effects of Medicare price and HMO penetration, but not market structure.

Shen finds a negative and significant relationship between the change in Medicare price and mortality. The interaction between the market structure and Medicare price variable is negative and significant for 1990-1994, but has no significant impact on mortality for 1985-1990. These results are consistent with standard theory. Hospitals respond to an increase in the regulated price by increasing quality. This response is amplified when hospitals face more competitors.

The effects of HMO penetration also appear to be roughly consistent with theory. Shen finds that HMO penetration leads to higher mortality, and that hospitals in markets with more competitors appeared to respond to HMO penetration with quality reductions in 1985-1990, although not thereafter. HMOs are hypothesized to increase the price elasticity of demand facing hospitals. If so, then the increased price elasticity will likely lead to a quality reduction. This should be amplified in markets with more competitors, since that should also increase the price elasticity. Shen also does a simple normative analysis of the effects of financial pressure, but not the effects of competition.

A paper by Tay (2003) takes a more structural approach. Tay specifies and estimates a structural econometric model of hospital choice by Medicare enrollees with AMI. ${ }^{33}$ Tay uses data on urban enrollees

\footnotetext{
${ }^{32}$ There have been a number of studies assessing the impact of the change in Medicare hospital payment from cost-plus to fixed price (the Medicare Prospective Payment system). See, for example, Kahn et al. (1990); Cutler (1995).

${ }^{33} \mathrm{~A}$ number of papers have previously examined whether choice of hospital is affected by quality (Luft et al., 1990; Burns and Wholey, 1992; Chernew et al., 1998). These studies find
} 
in conventional Medicare, located in California, Oregon, and Washington in 1994. She examines the effect of a number of aspects of quality and distance on the probability a patient is admitted to a particular hospital. The quality measures include two clinical outcomes: the mortality rate and the complication rate; a measure of input intensity: nurses per bed; and whether the hospital can perform two high-tech cardiac services: catheterization or revascularization. All measures of quality are treated as exogenous.

Tay finds that hospital demand is negatively affected by patient distance and positively affected by quality. She then simulates the effects of changes in the various aspects of a hospital's quality, holding the total number of heart attack patients fixed, the locations of patients and hospitals fixed, and the qualities of all other hospitals fixed. Adopting a catheterization lab is predicted to increase demand by 65 percent, while adding revascularization in addition to catheterization increases demand by 76 percent. If the number of nurses per bed is increased by one percent, then demand is predicted to increase by 24 percent.

Tay shows that hospital demand is significantly affected by quality and distance, thus there are potentially high payoffs to hospitals increasing quality. While this represents an advance over the previous literature by using more detailed modelling, there are nonetheless some limitations to the inferences that can be drawn from this study.

As with the previous studies, the Medicare price is omitted. It is possible that this omission is inconsequential, but I see no way to tell. Tay assumes that hospitals set the same level of quality for Medicare and non-Medicare patients. This is also an untested assumption, although it is at least explicit.

More fundamentally, the supply side of the market

that clinical quality, as measured by deviation between expected and actual mortality rates, has a significant impact on hospital choice - hospitals with lower mortality are more likely to be chosen. The responsiveness found in these studies indicates the potential for quality competition among hospitals, although how much is not clear, since the studies were not designed to assess this. is not modelled. As a consequence, competition itself is not modelled and can not be examined explicitly. There is no structure in place for dealing with the potential endogeneity of the quality variables. There is the usual reason to be concerned about endogeneity, since quality is chosen by the firm. In addition, it has been observed for a number of hospital procedures that hospital volume causes patient outcomes (see section 4.2.3 below for a review of some studies). This suggests endogeneity of the mortality and complication rates.

Further, the simulation is an out of equilibrium prediction. Tay's predicted effects of adding a catheterization lab or other services on demand are likely too large, since they hold rivals' responses fixed. If rivals respond by also adopting catherization labs or other services, then the equilibrium effects should be smaller, potentially even zero. It is also unclear whether firms would actually make the predicted choices. If rivals respond strongly to a firm's adoption of services, the responses may make adoption unprofitable. As a consequence it is hard to assess the magnitude of quality effects. Last, as Tay acknowledges, without a supply side no welfare analysis can be performed.

Most of these studies are quite recent. There are, however, two early studies that should be mentioned. Shortell and Hughes (1988) examine the association between in-hospital mortality among Medicare patients in 1983 and concentration. They find no statistically significant association, and the point estimate of the impact of concentration on mortality is small. Shortell and Hughes also examine the impact of stringency of state hospital price regulation programs and state regulation of hospital entry. They find that mortality was significantly worse in states with stringent price regulation and strict entry restrictions. This is exactly as the theory predicts - if the regulated price is lower, quality will be lower as well. Entry restriction will lead to lower quality.

Held and Pauly (1983) examines the competition and quality in the dialysis market. All people with end stage renal disease (ESRD, i.e., kidney failure) in the U.S. are covered by Medicare. Medicare pays a 
fixed price to dialysis facilities for treating patients. They use data on dialysis facilities in large urban areas of the U.S. in 1977 and 1978. The measure of quality is dialysis machines per patient. The notion is that greater capacity translates into greater convenience for patients in scheduling appointments. They regress the HHI for dialysis facilities on the number of dialysis machines per patient, including a number of control variables. The Medicare price is omitted, because there is no variation in the price in the sample. Held and Pauly find that there are more dialysis machines per patient in less concentrated areas. Hence, competition increases quality. Held and Pauly recognize that they are unable to draw normative conclusions from their analysis.

\subsection{Studies with Prices Set by Firms}

I now turn my attention to econometric studies of competition and quality where prices are set by firms. I will subdivide these studies into three categories. The first consists of older studies of the "Medical Arms Race." The second are newer studies that examine the impact of competition on hospital quality either via the SCP model or examining the impacts of mergers or price deregulation. The results are summarized in Table 4 . The last category are papers studying the relationship of hospital volume of specific procedures to patients' clinical outcomes. The results of these studies are summarized in Table 5 . In both tables the entry in the column labelled "Effect of Competition on Quality" indicates the direction of the relationship between the competition measure and the quality measure. The measure of quality used in the study is listed under the column heading "Quality Measure," and the measure of competition is listed in the column labeled "Competition Measure." For example, in the first row, the study by Joskow finds that his quality measure, excess bed capacity, is lower in more competitive markets, as indicated by the HHI.

\subsubsection{Older Studies — "Medical Arms Race"}

There are a number of studies of what has been dubbed "The Medical Arms Race." These studies examine the impact of competition on a number of measures of quality, usually facilities rather than clinical quality. They cover the period in the 1970s and 1980s when it was generally agreed that price competition among hospitals was weak or nonexistent. The notion was that, since price competition was weak, then competition must occur over non-price attributes. ${ }^{34}$ If we accept that price competition during this period is essentially nonexistent, then these studies should be regarded as similar to studies of competition with regulated prices, in contrast to the more recent studies I discuss below, which occur during a period in which there is clearly vigorous price competition.

This literature typically regresses a measure of market concentration (often the HHI) on some measure of input use or costs. The medical arms race is to be detected via a negative correlation between concentration and the input measure. Evidence of a negative relationship is generally presumed to be evidence of welfare reducing non-price competition.

Examples of this literature are Joskow (1980); Robinson and Luft (1985); Dranove et al. (1992). Joskow examines the relationship between hospital reserve capacity (i.e., unoccupied beds) and the HHI for all U.S. hospitals in 1976. Joskow takes reserve capacity as quality. He finds that hospitals in less concentrated markets had more excess capacity. Based on the model of quality competition with regulated prices presented in Section 3.3, Joskow deduces that competition may lead to supra-optimal excess capacity in hospital markets. This may be correct, but unlike the model, prices are not fixed. Without a fuller examination of price determination in hospital markets at that time, or of the costs associated with excess capacity, it isn't possible to make a determination about the welfare impacts of non-price competition.

\footnotetext{
${ }^{34}$ See Lyon (1999) for a model that generates this in equilibrium.
} 
Robinson and Luft (1985) study the impact of market structure on inpatient admissions, outpatient visits, length of stay and average costs for California hospitals in 1972. They use indicators of the number of other hospitals within a 15 mile radius of a hospital as measures of market structure, and regress those on their outcome variables. Robinson and Luft find that hospitals with more neighbors within 15 miles have more inpatient admissions and higher costs per case and per day, although there is no impact on outpatient visits or length of stay. Quality is unobserved. Presumably hospitals with more neighbors face tougher competition and are supplying higher quality, leading to the estimated positive relations between number of neighbors and admissions and costs. They infer that hospital competition is welfare reducing. Although the correlations this study turned up are interesting, it is not clear how to interpret them, either positively or normatively. The relationships they estimate are not derived from any obvious economic model, which makes interpretation difficult.

Dranove et al. (1992) examine hospital adoption of sophisticated medical technologies. They utilize 1983 hospital data from California, and examine the impact of the HHI and market size on the number of hospitals in the market adopting particular technologies. Dranove et al. find that the HHI has a negative impact on the number of hospitals adopting these technologies, i.e., there is more adoption in less concentrated markets. They also find, however, a very strong effect of market size on adoption. They interpret their results as providing evidence that market size is more important than market concentration, although the results do provide at least weak support for the medical arms race hypothesis.

Noether (1988) uses a slightly different methodology. She uses data on prices and expenses for 11 frequent diagnoses in all U.S. hospitals located in SMSAs from 1977 and 1978. She finds that less concentrated markets have lower prices and higher expenses, although the effect is weak and small. Thus this paper provides some moderate support for the existence of both price and non-price competition among hospitals in the 1970 s.

\subsubsection{Recent Studies}

There have been a number of more recent studies of competition and quality in hospital markets. These all cover time periods from the 1990s or later, when it is generally agreed that price competition had emerged in hospital markets. I will first discuss SCP studies, then cover merger studies, then finally move to studies of price deregulation. In considering these studies we need to refer back to the theory for guidance. Unlike the case of regulated prices, economic theory on competition and quality is less clear. Nonetheless, theory does provide a guide to what to look for, and what economic factors might be underlying an estimated relationship.

The study by Gowrisankaran and Town (2003) examined the relationship between market structure and AMI and pneumonia mortality in Los Angeles county in the early 1990s for both Medicare and HMO patients. I discussed the findings for Medicare patients in the previous section. I now turn to HMO patients. Gowrisankaran and Town find that riskadjusted mortality is significantly lower in less concentrated parts of Los Angeles county. This implies that competition is quality increasing for HMO patients. Using equation (18) for guidance, we see that this could occur if the quality elasticity of demand is higher in less concentrated markets, or if the price elasticity is lower. Since we generally think that elasticities are higher with more competitors, the former seems plausible (and the latter does not).

Sohn and Rathouz (2003) study the impact of competition on risk-adjusted mortality for patients receiving percutaneous transluminal coronary angioplasty (PTCA) in 116 hospitals in California in 1995. They construct a "competition coefficient" that varies between zero and one depending on the degree of overlap in the patient pools of a pair of hospitals. Sohn and Rathouz find that mortality is lower for patients in hospitals facing more competition. This effect is stronger in lower volume hospitals. Again, this result seems to imply that the quality elasticity is higher in more competitive markets.

Mukamel et al. (2002) examine the impact of com- 
petition on risk-adjusted mortality for California patients in 1982 and 1989. The two years cover the period before and after the introduction of insurer selective contracting in California. They hypothesize that the introduction of selective contracting increased price competition and that hospitals responded by shifting resources from clinical activities, which are hard to observe, to hotel activities, which are more easily observed. Mukamel et al. estimate the effects of the level of hospital concentration (measured as the $\mathrm{HHI}$ ) in the base year and the change in hospital concentration on the change in inpatient clinical expenditures, and then the impact of the change in expenditures and the level of the hospital HHI in 1989 on the level of risk-adjusted mortality in 1989. They find that the change in the HHI had a negative and significant impact on both clinical and hotel expenditures for not-for-profit hospitals, but no significant impact on for-profit hospitals. The estimated relationship between clinical expenditures and mortality is negative. Mukamel et al. find that together these two results imply that increased competition from 1982-1989 led to increased mortality, operating via competition reducing clinical expenditures on patients. The introduction of selective contracting is likely to have increased the price elasticity of demand facing hospitals, without increasing the quality elasticity by a similar proportion. In this case, the Dorfman and Steiner model predicts that quality will fall.

Encinosa and Bernard (2005) use data on all inpatient discharges from Florida hospitals from 1996 to 2000 to examine the impacts of financial pressure on patient safety. Encinosa and Bernard employ a newly available set of quality indicators developed by the Agency for Health Care Research and Quality (AHRQ). These indicators measure a variety of factors reflecting clinical quality, including mortality, obstetric complications, adverse or iatrogenic complications, wound infections, surgery complications, caesarean section, and inappropriate surgery. ${ }^{35}$ Encinosa and Bernard estimate the impact of within

\footnotetext{
${ }^{35}$ Go to http://http://www.qualityindicators.ahrq.gov for more information.
}

hospital changes in lagged operating profit margins ${ }^{36}$ on the probabilities of adverse patient safety events. They find that patients at hospitals in the lowest quartile of operating profit margins have significantly higher probabilities of adverse safety events than those in any of the higher quartiles. There are no significant differences in the probability of adverse events between patients in the highest, secondhighest, or third-highest quartiles. ${ }^{37}$ Thus patients at hospitals that are doing poorly financially are at greater risk of suffering from a patient safety problem than those who are at hospitals that are doing better financially. There seems to be no impact of doing better financially above a threshold (bottom quartile of operating margin).

This finding is roughly consistent with theory. We expect that quality will be positively related to marginal profits, so the empirical finding that quality is lower at hospitals with low profits seems likely. Standard theory would predict a continuous effect of profits on quality, however, not a threshold. It is possible that this could be due to data limitations. Encinosa and Bernard have to rely on accounting data, so they are unable to measure economic profits or construct a measure of marginal profits.

There are also some issues with the econometrics. Encinosa and Bernard use hospital dummies to control for hospital-specific unobserved factors. The estimating equations are logits for the probabilities of adverse patient safety events. This is a nonlinear estimator, so unlike least squares, hospital-specific effects are not differenced away. As a consequence, it isn't clear to what extent their estimates of the effects of profits on safety are truly purged of potentially confounding hospital-specific effects. Another issue is that slope estimates from nonlinear models with group fixed effects are only consistent when the number of observations per group goes to infinity. In this context, that means that the number of years

\footnotetext{
${ }^{36}$ The ratio of net operating profit to net operating revenue.

${ }^{37}$ The first quartile covers patients at hospitals with margins below $-0.5 \%$. The second quartile covers margins between $0.5 \%$ and $4.4 \%$, the third between $4.4 \%$ and $9.3 \%$, and the fourth covers margins greater than $9.3 \%$.
} 
each hospital is observed has to be large. Since the sample in this paper covers 5 years, it seems unlikely this condition is met, hence the estimates may not be consistent.

While this study does not directly examine competition, it may have implications for the impact of competition on quality. To the extent that competition reduces hospital operating margins to low levels as in Encinosa and Bernard it may put patients at higher risk of adverse safety events.

Propper et al. (2004) use an SCP approach to examine the effect of the effect of hospital competition in the United Kingdom following reforms to the National Health Service in the 1990s. These reforms encouraged payer-driven competition among hospitals. Propper et al. examine the impact of this payerdriven competition on mortality for AMI patients. They examine the impact of a measure of market structure (roughly, the number of competitors) on mortality over the period 1995-1998 and find that mortality increases with the number of competitors. This finding certainly contrasts with that of U.S. SCP studies, but (for better or for worse) it is consistent with theory. The presence of more competitors can increase quality elasticity, price elasticity, or both. If the price elasticity increases more than the quality elasticity, then quality will fall. Whether this is the mechanism driving the result in this paper can not be determined, although it provides some direction for future research. As previously, the welfare impacts of this finding are unclear. If increasing the number of competitors is associated with a decrease in market power, then a quality decrease may be welfare improving. Alternatively, it could be harmful.

An interesting study is by Sari (2002). Sari uses the same quality indicators as Encinosa and Bernard. Sari is one of the first studies to employ these indicators rather than following the common practice of using risk-adjusted mortality as a quality measure. He employs data on hospitals in 16 states covering the period 1992-1997 and estimates the SCP model using fixed effects, random effects, and instrumental variables with fixed effects. Sari finds that quality is significantly lower in more concentrated markets
- he estimates that a 10 percent increase in hospital market share leads to a 0.18 percent decrease in quality. He also finds evidence that managed care penetration increases quality for some of the quality indicators, although there is no statistically significant relationship for others.

Ho and Hamilton (2000) and Capps (2005) are two papers that examine the impact of hospital mergers on quality of care. Ho and Hamilton (2000) study 130 hospital mergers of various types over the period 1992 to 1995 . The quality measures they employ are inpatient mortality, readmission rates, and early discharge of newborns. They employ hospital specific fixed effects to control for time invariant hospital characteristics that may be related to merger. Ho and Hamilton find no detectable impact of merger on mortality for either heart attack or stroke patients. They do find that some mergers increase readmission rates for heart attack patients and the early discharge of newborns. It is unclear whether Ho and Hamilton find no effect because there truly is no effect or because they are unable to identify the effect in the data. The effects of mergers are notoriously difficult to identify. First, there are not a large number of mergers, so there is not a lot of statistical power with which to detect an effect. Second, the identifying variation in this study comes from within-hospital variation over time. If that is not the primary source of variation in outcomes then the estimates of the parameters will be imprecise. Third, mergers are certainly endogenous. Mergers occur for reasons that are often related to the outcome variables of interest. If mergers occur for reasons related to hospitals' changing circumstances over time, then the hospital fixed effects will not control for endogeneity, so it will be difficult to obtain consistent estimates of a merger effect.

Capps (2005) uses the AHRQ quality indicators to examine the effect of hospital mergers on quality. He compares merging to non-merging hospitals in New York state during 1995-2000. There are 25 merging hospitals, and 246 total. Control groups are constructed in 2 ways. The first method is to select non-merging hospitals that are similar to merging hospitals in observable characteristics (e.g., teaching 
status, size, ownership, etc.). The second method is to use propensity scores to identify a control group. The control group for a merging hospital then consists of the ten non-merging hospitals that have predicted probabilities of merging that are closest to the predicted probability of the merging hospital.

Using the first method Capps finds no statistically significant effect of mergers on most of the quality indicators. There is no effect on 4 of 6 inpatient indicators for quality procedures, no effect for indicators for 3 other surgical procedures, and no effect for 6 patient safety indicators. Merger is found to have a negative effect on the inpatient quality indicators for 2 cardiac procedures: AMI and congestive heart failure (CHF). Merger is estimated to lead to an additional 12 deaths per 1,000 AMI or CHF admissions in the year following the merger, although there is no significant effect in the second year after the merger. There are no statistically significant effects of merger on any of the quality indicators when propensity scores are used to generate a control group. As with the Ho and Hamilton paper it is hard to know how to interpret the overall lack of statistical significance. Mergers may truly have had no impact on hospital quality in New York state over this period, or it may just be very difficult to precisely test the hypothesis.

Two very interesting recent papers use changes in regulation as a way to learn about the effect of hospital competition on quality. Volpp et al. (2003) study the effect of the deregulation of hospital prices in New Jersey to try and learn about the impact of the introduction of price competition on hospital quality. In 1992 New Jersey deregulated hospital prices. The neighboring state of New York had no change in its hospital regulatory regime. Volpp et al. use data on AMI hospital admissions in New Jersey and New York from 1990 to 1996 to learn about the effect of the deregulation. They look at the difference in riskadjusted inpatient AMI mortality between New Jersey and New York before and after regulatory repeal. They find that mortality in New Jersey relative to New York increased after price deregulation. At first glance this result contrasts markedly with the SCP type studies previously discussed. However, consider the impact of price deregulation. The biggest impact should be to increase the price elasticity of demand, and decrease price. ${ }^{38}$ The quality elasticity seems unlikely to be significantly affected. The prediction of the Dorfman and Steiner type model is that quality will fall when the price elasticity of demand increases. It is impossible to say what the impact on welfare might be. If the regulated prices were set too high, then this quality decrease is welfare increasing, and vice versa.

A paper by Propper et al. (2003) employs a similar approach to Volpp et al. In this paper Propper et al. (2003) examine the impacts of competitive reforms in the NHS on mortality for AMI patients. Propper et al. (2003) use a different strategy in this paper than in Propper et al. (2004). Here they use the change in regulation in the U.K. over the period 1991-1999, combined with geographic variation in the number of competitors. $^{39}$ Competition was introduced in 1991 and actively promoted up until 1995. It was downplayed after 1995 and actively discouraged from 1997 onwards. The impact of competition is identified by differences between hospitals facing competitors and those who are not between the time periods when competition was encouraged versus when it was discouraged.

Propper et al. (2003) find that competition reduces quality. The differences in mortality for hospitals in areas with competitors versus those with no competitors was higher during the period when competition was promoted (1991-1995), than during the period when competition was discouraged (1996-1998). The estimated cumulative effect of competition over the entire period is to raise mortality rates by roughly the same amount as the cumulative effect of the secular downward trend in heart attack mortality (presumably due to technological change). This is a large impact. As with Volpp et al. (2003), these results can be interpreted as consistent with the Dorfman and Steiner model, although that is not testable within

\footnotetext{
${ }^{38}$ Unfortunately Volpp et al. do not have any evidence on the effect of deregulation on prices.

${ }^{39}$ Only variation in the number of competitors is used in Propper et al. (2004).
} 
the framework employed in the paper. Also as before, the welfare inferences are unclear.

Howard (2005) is a recent paper that focuses on demand, as in the paper by Tay. Howard models the demand for kidney transplantation facilities, focusing on the effect of quality on consumer choice of facility. Howard examines the choices of all patients receiving transplants, including Medicare patients, Medicaid patients, and those with private insurance.

Quality is measured as the difference between expected and actual one year post-transplant graft failure rates at a center. Howard assumes that there are no price differences that affect choice between transplant centers, thus price is omitted. The explanatory variables are the quality measure, patients' distances from transplant centers, and patient characteristics. The average estimated choice elasticity with respect to quality is -0.12 . The quality elasticity for privately insured patients is larger: -0.22 .

These elasticity estimates are not particularly large. The low value of the average estimated quality elasticity implies that this does not give transplant centers a large incentive to compete on quality, as indicated by equation (29). Since Howard does not model the supply side, his model doesn't directly predict the impacts of competition (it is not intended to do so).

As with the Tay paper there are also some concerns about price and endogeneity. Howard assumes that price has no impact on where patients obtain their transplants. This may be true for Medicare, but it seems unlikely for patients who are privately insured. Privately insured patients face very large differences in out of pocket costs between providers that are in and out of their coverage networks. In addition, health insurance plans make decisions on which providers to include in their networks based on price. Thus it seems as if price should be included for those with private insurance. Further, if price is positively correlated with quality, then its omission could lead to a downward bias in the estimated effect of quality on demand. Patients may appear less responsive to quality differences than they really are if high quality transplant centers are also high cost to them. Endogeneity of quality may also be an issue, for the same reasons as the Tay paper.

Abraham et al. (2005) is one of the few studies with clear welfare implications. Abraham et al. examine the determinants of the number of hospitals in isolated markets in the U.S. for 1990. They do not examine price or quality explicitly. Instead, they infer whether competition is increasing by the population required to support another firm in the market. If the population required to support another firm is increasing, then average profits available post-entry must be decreasing, thus increasing the volume necessary to make entry profitable. They find that market size is the primary determinant of the number of hospitals, and that the quantity bought and sold in the market rises, and variable profits fall, as the number of hospitals in a local market increases. This implies that the market is getting more competitive as the number of hospitals increase. Further, it shows that entry isn't simply demand-stealing — more hospitals increase demand. The reason is that quantity demanded can increase only if price is lower or quality is higher. Since that does happen, people are consuming more and must be better off. As a consequence, they conclude that competition increases with the number of hospitals, and that competition is welfare improving.

\subsubsection{Studies of the Volume-Outcome Rela- tionship}

There have been a very large number of studies of the "volume-outcome" relationship, the majority in the medical literature. These studies commonly find a significant correlation with the volume a hospital does of a procedure and the medical outcomes of patients receiving the procedure at that hospital. The obvious concern with studies of this kind is endogeneity. It may be that hospitals that do more of a procedure are better at it, whether from learning by doing or by making quality improving investments. It may also be true, however, that patients are attracted to hospitals with the best outcomes. The studies in the medical literature are unable to distinguish between 
these two alternatives.

This is important for assessing competition in the hospital sector and for antitrust enforcement. If volume causes quality, then there may be some efficiencies from improved patient outcomes in more concentrated markets. This could also affect hospital merger evaluation. I review three relatively recent studies below that present the strongest evidence to date on the volume-outcome effect: Ho (2002), Gowrisankaran et al. (2004), and Gaynor et al. (2005). The results of these studies are summarized in Table 5.

Ho (2002) examines the volume outcome relationship for PTCA using data from California hospitals from 1984 to 1996. The outcomes she examines are mortality and emergency CABG. She estimates the effects of hospital cumulative and annual volume on outcomes, employing hospital and time fixed effects. Ho finds substantial improvements in outcomes over time, but a small effect of annual hospital volume on outcome. The effect of cumulative volume on outcomes is imprecisely estimated.

Gowrisankaran et al. (2004) attempt to recover the causal relationship between volume and outcome using instrumental variables. They study the volumeoutcome relationship for three surgical procedures: the Whipple procedure (removing tumors from the pancreas); CABG; and repair of abdominal aortic aneurysm (AAA - this repairs weak spots in the abdominal artery). They use data on hospitals from Florida from 1988 to 1999 and California from 1993 to 1997 . The instrumental variables approach is to use patient distance from the hospital to estimate patient choice of hospital and then construct predicted volume. Gowrisankaran et al. find that increasing volume causes better outcomes for all three procedures and find significant and large effects of hospital volume on patient mortality. This implies that volume-outcome effects can be important to consider when evaluating the impact of hospital competition. If competition leads to reduced volume then outcomes will decline. If competition leads to specialization then outcomes will improve.

Gaynor et al. (2005), in a similar paper, use instrumental variables techniques to estimate the vol- ume outcome relationship for CABG. They use data from California for 1983-1999. Gaynor et al. find a causal, and substantial, effect of volume on outcome. For example, if CABGs could only be performed in hospitals with a volume of 200 or greater, the average mortality rate from CABG would fall from 2.5 percent to 2.05 percent, saving 118 (statistical) lives. In a related working paper by the same authors, Seider et al. (2000), simulate the effects of two mergers: a hypothetical "standard merger", in which two out of five firms with equal market shares merge; and the actual merger of Alta Bates Medical Center and Summit Medical Center in Oakland, California. They find that, for larger hospital mergers (hospital volumes $>140$ ), the value of saved lives from the standard merger outweighs the loss of consumer surplus from increased prices. For the Summit-Alta Bates merger, which does not, however, have a large effect on volume, the effect is a net loss of $\$ 2.8$ to $\$ 4.4$ million. The reason is that the increase in volume due to the merger is too small to have much effect on outcomes, while the price increase reduces welfare.

\section{$5 \quad$ Summary and Conclusions}

In this paper I have reviewed the literature relevant to competition and quality in health care markets. Economic theory does not provide an unambiguous answer to the question of whether competition is welfare enhancing in markets with product differentiation, although it provides guidance for thinking about the issues. The empirical literature on competition and quality in health care markets is for the most part fairly recent, and growing rapidly. The results from empirical research are not uniform. Most of the studies of Medicare patients show a positive impact of competition on quality. This is not surprising, since economic theory for markets with regulated prices predicts such a result. However, the results from studies of markets where prices are set by firms (e.g, privately insured patients) are much more variable. Some studies show increased competition leading to increased quality, and some show the opposite. While this may appear surprising, it is not. 
Economic theory predicts that quality may either increase or decrease with increased competition when firms are setting both quality and price.

This first generation of studies has provided a very valuable base of knowledge for further research. The base that has been constructed, while extremely useful, does not allow for normative analysis, for the most part. The results of these studies don't allow us to make inferences about whether their estimated results imply that competition increased or decreased social welfare.

A major next step for research in this area is sorting out the factors that determine whether competition will lead to increased or decreased quality. Economic theory can be a helpful guide for these next generation studies. While theoretical models of price and quality determination are complex and usually yield indefinite predictions, there is also some simple intuition that can be gleaned from theory. Whether competition leads to increased or decreased quality will depend on its relative impacts on firms' price and quality elasticities of demand. Future research can focus on trying to recover estimates of these key elements. Additionally, studies of price regulated markets can refer back to theory to specify econometric models that include the regulated price and marginal cost (or its determinants). These sorts of studies will allow for more precise positive analysis of the impact of competition on quality in health care.

We need more detailed models, however, in order to perform normative analysis. Thus, an important, although formidable task, for future work is to pursue the estimation of more complete econometric models of quality determination in health care markets. This means trying to recover preferences and costs (i.e., demand and supply). The benefit of this approach is the ability to make clearer inferences about welfare, since estimates of preference and cost parameters are in hand. The drawback is that such estimates are not easily obtained. In particular, they usually can only be obtained at the cost of making untestable assumptions. The quantity, and detail, of health care data may make some of the assumptions employed in settings with sparser data unnecessary, however.
There are three other directions for future studies to pursue. First, measures of health care quality are becoming more common and more sophisticated. Future studies can begin to employ these new measures. Second, most of the studies to date have focused on a single measure of health care quality, and often for a single condition. A task for future work is to try to develop broader evidence on the impact of competition on various aspects of health care quality. Third, the study of the impact of competition on quality should be extended to other parts of the health care sector - most notably physician services and health insurance.

Market oriented health care system reforms are being considered by quite a few countries. U.S. courts have to make decisions about antitrust issues involving health care firms. Evidence on the impacts of competition on quality in health care is vital to the policy decisions these individuals must make. There is considerable scope for future research to contribute to policy on this issue. 


\section{References}

Abraham, J. M., Gaynor, M., and Vogt, W. B. (2005). Entry and competition in local hospital markets. unpublished manuscript, Carnegie Mellon University.

Allard, M., Léger, P. T., and Rochaix, L. (2005). Provider competition in a dynamic setting. unpublished manuscript, HEC Montréal.

Allen, F. (1984). Reputation and product quality. RAND Journal of Economics, 15(3):311-327.

Allen, R. and Gertler, P. J. (1991). Regulation and the provision of quality to heterogeneous consumers. Journal of Regulatory Economics, 3:60-75.

Anderson, S., dePalma, A., and Thisse, J. (1992). Discrete choice theory of product differentiation. MIT Press.

Bresnahan, T. F. (1989). Empirical studies of industries with market power. In Schmalensee, R. and Willig, R., editors, Handbook of Industrial Organization, volume 2, chapter 17, pages 1011-1057. Elsevier Science, North-Holland, Amsterdam and New York.

Burns, L. R. and Wholey, D. R. (1992). The impcat of physician characteristics in conditional choice models for hospital care. Journal of Health Economics, 11(1):43-62.

Capps, C. (2005). The quality effects of hospital mergers. unpublished manuscript.

Carlton, D. W. and Perloff, J. M. (2005). Modern Industrial Organization. Addison-Wesley, Boston, MA.

Chernew, M., Scanlon, D., and Hayward, R. (1998). Insurance type and choice of hospital for coronary artery bypass graft surgery. Health Services Research, 33(3):447-466.

Cutler, D. M. (1995). The incidence of adverse medical outcomes under prospective payment. Econometrica, 63(1):29-50.
Dixit, A. and Stiglitz, J. E. (1977). Monopolistic competition and optimum product diversity. American Economic Review, 67:297-308.

Dorfman, R. and Steiner, P. (1954). Optimal advertising and optimal quality. American Economic Review, 44(5):826-836.

Douglas, G. W. and Miller, J. C. (1974). Quality competition, industry equilibrium, and efficiency in the price-constrained airline market. American Economic Review, 64(4):657-669.

Dranove, D. D. and Satterthwaite, M. A. (1992). Monopolistic competition when pirce and quality are imperfectly observable. Rand Journal of Economics, 23(4):518-534.

Dranove, D. D. and Satterthwaite, M. A. (2000). The industrial organization of health care markets. In Culyer, A. and Newhouse, J., editors, Handbook of Health Economics, chapter 20, pages 1094-1139. Elsevier Science, North-Holland, New York and Oxford.

Dranove, D. D., Shanley, M., and Simon, C. (1992). Is hospital competition wasteful? Rand Journal of Economics, 23:247-262.

Eaton, B. C. and Lipsey, R. G. (1989). Product differentiation. In Schmalensee, R. and Willig, R., editors, Handbook of Industrial Organization, volume 1, chapter 12, pages 723-768. Elsevier Science, North-Holland, Amsterdam and New York.

Encinosa, W. E. and Bernard, D. M. (2005). Hospital finances and patient safety outcomes. Inquiry, $42(1): 60-72$.

Federal Trade Commission (2004). Horizontal merger investigation data, fiscal years 1996-2003. Report, Federal Trade Commission, Washington, D.C., February 2, Revised August 31.

Federal Trade Commission and Department of Justice (1992). Horizontal merger guidelines. Issued April 2, 1992, Revised April 8, 1997. 
Frankena, M. W. and Pautler, P. A. (1984). An economic analysis of taxicab regulation. Bureau of economics staff report, Federal Trade Commission, Washington, D.C.

Gabel, J., Levitt, L., Pickreign, J., Whitmore, H., Holve, E., Hawkins, S., and Miller, N. (2000). Job-based health insurance in 2000: Premiums rise sharply while coverage grows. Health Affairs, 19(5):144-151.

Gaynor, M. (2004). Quality and competition in health care markets: What do we know? what don't we know? Économie Publique, 15(2):87-124.

Gaynor, M. and Haas-Wilson, D. (1999). Change, consolidation, and competition in health care markets. Journal of Economic Perspectives, 13(1):14164 .

Gaynor, M., Seider, H., and Vogt, W. B. (2005). Is there a volume-outcome effect and does it matter? Yes, and yes. American Economic Review, Papers and Proceedings, 95(2):243-247.

Gaynor, M. and Vogt, W. B. (2000). Antitrust and competition in health care markets. In Culyer, A. and Newhouse, J., editors, Handbook of Health Economics, chapter 27, pages 1405-1487. Elsevier Science, North-Holland, New York and Oxford.

Gaynor, M. and Vogt, W. B. (2003). Competition among hospitals. Rand Journal of Economics, 34(4):764-785.

Gowrisankaran, G., Ho, V., and Town, R. (2004). Causality and the volume-outcome relationship in surgery. unpublished manuscript, University of Minnesota.

Gowrisankaran, G. and Town, R. (2003). Competition, payers, and hospital quality. Health Services Research, 38:1403-1422.

Hammer, P. J. and Sage, W. M. (2002). Antitrust, health care quality, and the courts. Columbia Law Review, 102(3):545-649.
Held, P. J. and Pauly, M. V. (1983). Competition and efficiency in the end stage renal disease program. Journal of Health Economics, 2(2):95-118.

Ho, V. (2002). Learning and the evolution of medical technologies: The diffusion of coronary angioplasty. Journal of Health Economics, 21(5):873885.

Ho, V. and Hamilton, B. H. (2000). Hospital mergers and acquisitions: does market consolidation harm patients? Journal of Health Economics, 19(5):76791.

Hotelling, H. (1929). Stability in competition. Economic Journal, 39(153):41-57.

Howard, D. H. (2005). Quality and consumer choice in healthcare: Evidence from kidney transplantation. Topics in Economic Analysis and Policy, 5(1):Article 24, 1-20. http://www.bepress.com/ bejeap/topics/vol5/iss1/art24.

Institute of Medicine (2001). Crossing the Quality Chasm: A New Health System for the Twenty-First Century. National Academy Press, Washington, D.C.

Jaklevic, M. (2002). "Tired Trend". Modern Healthcare, $32(26): 10$.

Joskow, P. L. (1980). The effects of competition and regulation on hospital bed supply and the reservation quality of the hospital. Bell Journal of Economics, 11:421-447.

Kahn, K. L., Keeler, E. B., Sherwood, M. J., Rogers, W. H., Draper, D., Bentow, S. S., Reinisch, E. J., Rubenstein, L. V., Kosecoff, J., and Brook, R. H. (1990). Comparing outcomes of care before and after implementation of the DRG-based prospective payment system. Journal of the American Medical Association, 264(15):1984-1988.

Kamien, M. I. and Vincent, D. R. (1991). Price regulation and the quality of service. Discussion Paper No. 920, Center for Mathematical Studies in Economics and Management Science, Northwestern University. 
Kessler, D. and McClellan, M. (2000). Is hospital competition socially wasteful? Quarterly Journal of Economics, 115(2):577-615.

Kessler, D. P. and Geppert, J. J. (2005). The effects of competition on variation in the quality and cost of medical care. Journal of Economics and Management Strategy, 14(3):575-589.

Klein, B. and Leffler, K. (1981). The role of market forces in assuring contractual performance. Journal of Political Economy, 89(4):615-641.

Kohn, L., Corrigan, J., and Donaldson, M., editors (1999). To Err is Human: Building a Safer Health System. National Academy Press, Washington, DC.

Kranton, R. E. (2003). Competition and the incentive to produce high quality. Economica, 70(279):385404.

Lakdawalla, D. and Philipson, T. (1998). Nonprofit production and competition. Working Paper \#6377, National Bureau of Economic Research.

Lee, M. (1971). A conspicuous production theory of hospital production. Southern Economic Journal, 38(1):48-58.

Lesser, C. and Ginsburg, P. (2001). Back to the future? New cost and access challenges emerge: Initial findings from HSC's recent site visits. Issue Brief \#35, Center for Studying Health Systems Change, Washington, D.C.

Luft, H. S., Garnick, D. W., Mark, D. H., Peltzman, D. J., Phibbs, C. S., Lichtenberg, E., and McPhee, S. J. (1990). Does quality influence choice of hospital? JAMA, 263(21):2899-2906.

Lyon, T. P. (1999). Quality competition, insurance, and consumer choice in health care markets. Journal of Economics and Management Strategy, $8(4): 545-580$.

Ma, C.-t. A. and Burgess, Jr., J. F. (1993). Quality competition, welfare, and regulation. Journal of Economics, 58(2):153-173.
Mankiw, N. G. and Whinston, M. (1986). Free entry and social inefficiency. Rand Journal of Economics, $17(1): 48-58$.

Mukamel, D., Zwanziger, J., and Bamezai, A. (2002). Hospital competition, resource allocation and quality of care. BMC Health Services Research, 2(1):10-18.

Mukamel, D., Zwanziger, J., and Tomaszewski, K. J. (2001). HMO penetration, competition and riskadjusted hospital mortality. Health Services Research, 36(6):1019-1035.

Mussa, M. and Rosen, S. (1978). Monopoly and product quality. Journal of Economic Theory, 18:301317 .

Newhouse, J. (1970). Toward a theory of nonprofit institutions: an economic model of a hospital. American Economic Review, 60(1):64-74.

Noether, M. (1988). Competition among hospitals. Journal of Health Economics, 7(3):259-284.

Nuscheler, R. (2003). Physician reimbursement, time consistency, and the quality of care. Journal of Institutional and Theoretical Economics, 159(2):302322 .

Pauly, M. and Redisch, M. (1973). The not-for-profit hospital as a physicians' cooperative. American Economic Review, 63(1):87-99.

Pepall, L., Richards, D. J., and Norman, G. (2005). Industrial Organization: Contemporary Theory and Practice. South-Western, Mason, $\mathrm{OH}$.

Pope, G. C. (1989). Hospital nonprice competition and medicare reimbursement policy. Journal of Health Economics, 8(2):147-172.

Propper, C., Burgess, S., and Gossage, D. (2003). Competition and quality: Evidence from the NHS internal market 1991-1999. Unpublished paper, University of Bristol.

Propper, C., Burgess, S., and Green, K. (2004). Does competition between hospitals improve the quality 
of care? hospital death rates and the nhs internal market. Journal of Public Economics, 88(78):1247-1272.

Robinson, J. C. and Luft, H. S. (1985). The impact of hospital market structure on patient volume, average length of stay, and the cost of care. Journal of Health Economics, 4:333-356.

Romano, P. (2003). Evolving science of quality measurement for hospitals and physicians: Promise and cautions. presented at AHRQ/FTC conference on provider quality and competition, May 28.

Sage, W. M., Hyman, D. A., and Greenberg, W. (2003). Why competition matters to health care quality. Health Affairs, 22(2):31-44.

Sari, N. (2002). Do competition and managed care improve quality? Health Economics, 11:571-584.

Schmalensee, R. (1977). Comparative static properties of regulated airline oligopolies. Bell Journal of Economics, 8(2):565-576.

Schmalensee, R. (1989). Inter-industry studies of structure and performance. In Schmalensee, R. and Willig, R., editors, Handbook of Industrial Organization, volume 2, chapter 16, pages 951-1009. Elsevier Science, North-Holland, Amsterdam and New York.

Seider, H., Gaynor, M., and Vogt, W. B. (2000). Volume-outcome and antitrust in us health care markets. unpublished manuscript, Universitaet Augsburg.

Shapiro, C. (1983). Premiums for high quality products as returns on reputation. Quarterly Journal of Economics, 98(4):659-680.

Shen, Y.-S. (2003). The effect of financial pressure on the quality of care in hospitals. Journal of Health Economics, 22(2):243-269.

Shortell, S. M. and Hughes, E. F. (1988). The effects of regulation, competition, and ownership on mortality rates among hospital inpatients. New England Journal of Medicine, 318:1100-1107.
Smith, C., Cowan, C., Heffler, S., Catlin, A., and the National Health Accounts Team (2006). National health spending in 2004: Recent slowdown led by prescription drug spending. Health Affairs, 25(1):186-196.

Sohn, M.-W. and Rathouz, P. J. (2003). Competition among hospitals and quality of care: hospitallevel analysis. unpublished paper, University of Chicago.

Spence, A. M. (1975). Monopoly, quality and regulation. Bell Journal of Economics, 6(2):417-429.

Spence, A. M. (1976). Product selection, fixed costs, and monopolistic competition. Review of Economic Studies, 43(2):217-235.

Tay, A. (2003). Assessing competition in hospital care markets: The importance of accounting for quality differentiation. Rand Journal of Economics, $34(4): 786-814$.

Tirole, J. (1988). The Theory of Industrial Organization. MIT Press, Cambridge, MA.

Vander Weide, J. H. and Zalkind, J. H. (1981). Deregulation and oligopolistic price-quality rivalry. American Economic Review, 71(1):144-154.

Volpp, K. G., Williams, S. V., Waldfogel, J., Silber, J. H., Schwartz, J. S., and Pauly, M. V. (2003). Market reform in New Jersey and the effect on mortality from acute myocardial infarction. Health Services Research, 38(2):515-533.

White, L. J. (1972). Quality variation when prices are regulated. Bell Journal of Economics and Management Science, 3(2):425-436. 
Table 1: Hospital Market Concentration, 1985-2000a

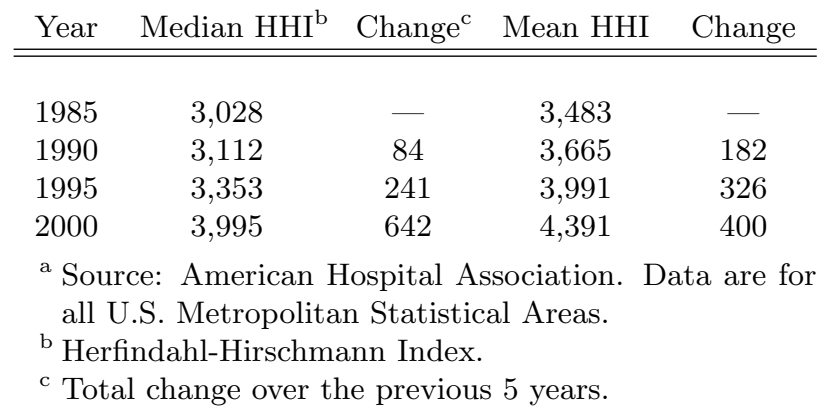


Table 2: Theoretical Results: Competition and Quality

\begin{tabular}{|c|c|c|c|c|}
\hline Study & $\begin{array}{l}\text { Price Regulated } \\
\text { or Set by Firm }\end{array}$ & $\begin{array}{l}\text { Type of Product } \\
\text { Differentiation }\end{array}$ & $\begin{array}{l}\text { Effect of } \\
\text { Competition on } \\
\text { Quality }\end{array}$ & $\begin{array}{l}\text { Competitive Quality } \\
\text { Relative to Social } \\
\text { Optimum }\end{array}$ \\
\hline Spence (1975) & Set by Firm & Product Quality &,,+- 0 & Larger/Smaller/Same \\
\hline $\begin{array}{l}\text { Mussa and Rosen } \\
\text { (1978) }\end{array}$ & Set by Firm & Product Quality & + & Same \\
\hline $\begin{array}{l}\text { Dranove and } \\
\text { Satterthwaite } \\
(1992)\end{array}$ & Set by Firm & Product Quality &,,+- 0 & Larger/Smaller/Same \\
\hline Kranton (2003) & Set by Firm & Product Quality & - & Smaller \\
\hline Allard et al. (2005) & Set by Firm & Product Quality & + & Same/Smaller \\
\hline Spence (1976) & Set by Firm & Product Variety &,,+- 0 & Larger/Smaller/Same \\
\hline $\begin{array}{l}\text { Dixit and Stiglitz } \\
(1977)\end{array}$ & Set by Firm & Product Variety &,,+- 0 & Larger/Smaller/Same \\
\hline $\begin{array}{l}\text { Mankiw and } \\
\text { Whinston (1986) }\end{array}$ & Set by Firm & Product Variety &,,+- 0 & Larger/Smaller/Same \\
\hline $\begin{array}{l}\text { Douglas and Miller } \\
(1974)\end{array}$ & Regulated & Product Quality & + & Larger/Smaller/Same \\
\hline $\begin{array}{l}\text { Vander Weide and } \\
\text { Zalkind (1981) }\end{array}$ & Regulated & Product Quality & + & Larger/Smaller/Same \\
\hline White (1972) & Regulated & Product Quality & + & Larger/Smaller/Same \\
\hline $\begin{array}{l}\text { Held and Pauly } \\
\text { (1983) }\end{array}$ & Regulated & Product Quality & + & Larger/Smaller/Same \\
\hline Pope (1989) & Regulated & Product Quality & + & Larger/Smaller/Same \\
\hline Allen and Gertler & Regulated & Product Quality & + & Larger/Smaller/Same \\
\hline
\end{tabular}


Table 2, continued

\begin{tabular}{|c|c|c|c|c|}
\hline Study & $\begin{array}{l}\text { Price Regulated } \\
\text { or Set by Firm }\end{array}$ & $\begin{array}{l}\text { Type of Product } \\
\text { Differentiation }\end{array}$ & $\begin{array}{l}\text { Effect of } \\
\text { Competition on } \\
\text { Quality }\end{array}$ & $\begin{array}{l}\text { Competitive Quality } \\
\text { Relative to Social } \\
\text { Optimum }\end{array}$ \\
\hline $\begin{array}{l}\text { Kamien and } \\
\text { Vincent (1991) }\end{array}$ & $\begin{array}{l}\text { Set by Firm } \\
\text { Regulated }\end{array}$ & $\begin{array}{l}\text { Product Quality } \\
\text { and Variety }\end{array}$ & $\begin{array}{l}\text { Set by Firm: - } \\
\text { Regulated: + }\end{array}$ & $\begin{array}{l}\text { Set by Firm: Smaller } \\
\text { Regulated: } \\
\text { Larger/Smaller/Same }\end{array}$ \\
\hline $\begin{array}{l}\text { Ma and Burgess } \\
(1993)\end{array}$ & $\begin{array}{l}\text { Set by Firm } \\
\text { Regulated }\end{array}$ & $\begin{array}{l}\text { Product Quality } \\
\text { and Variety }\end{array}$ & $\begin{array}{l}\text { Set by Firm: - } \\
\text { Regulated: + }\end{array}$ & $\begin{array}{l}\text { Set by Firm: Smaller } \\
\text { Regulated: Same }\end{array}$ \\
\hline Lyon (1999) & Set by Firm & $\begin{array}{l}\text { Product Quality } \\
\text { and Variety }\end{array}$ & $\begin{array}{l}\text { Traditional Health } \\
\text { Insurance: }+ \\
\text { Managed Care: }-,+\end{array}$ & $\begin{array}{l}\text { Traditional Health } \\
\text { Insurance: Larger } \\
\text { Managed Care: } \\
\text { Smaller/Larger }\end{array}$ \\
\hline Nuscheler (2003) & Regulated & $\begin{array}{l}\text { Product Quality } \\
\text { and Variety }\end{array}$ & + & Larger \\
\hline
\end{tabular}




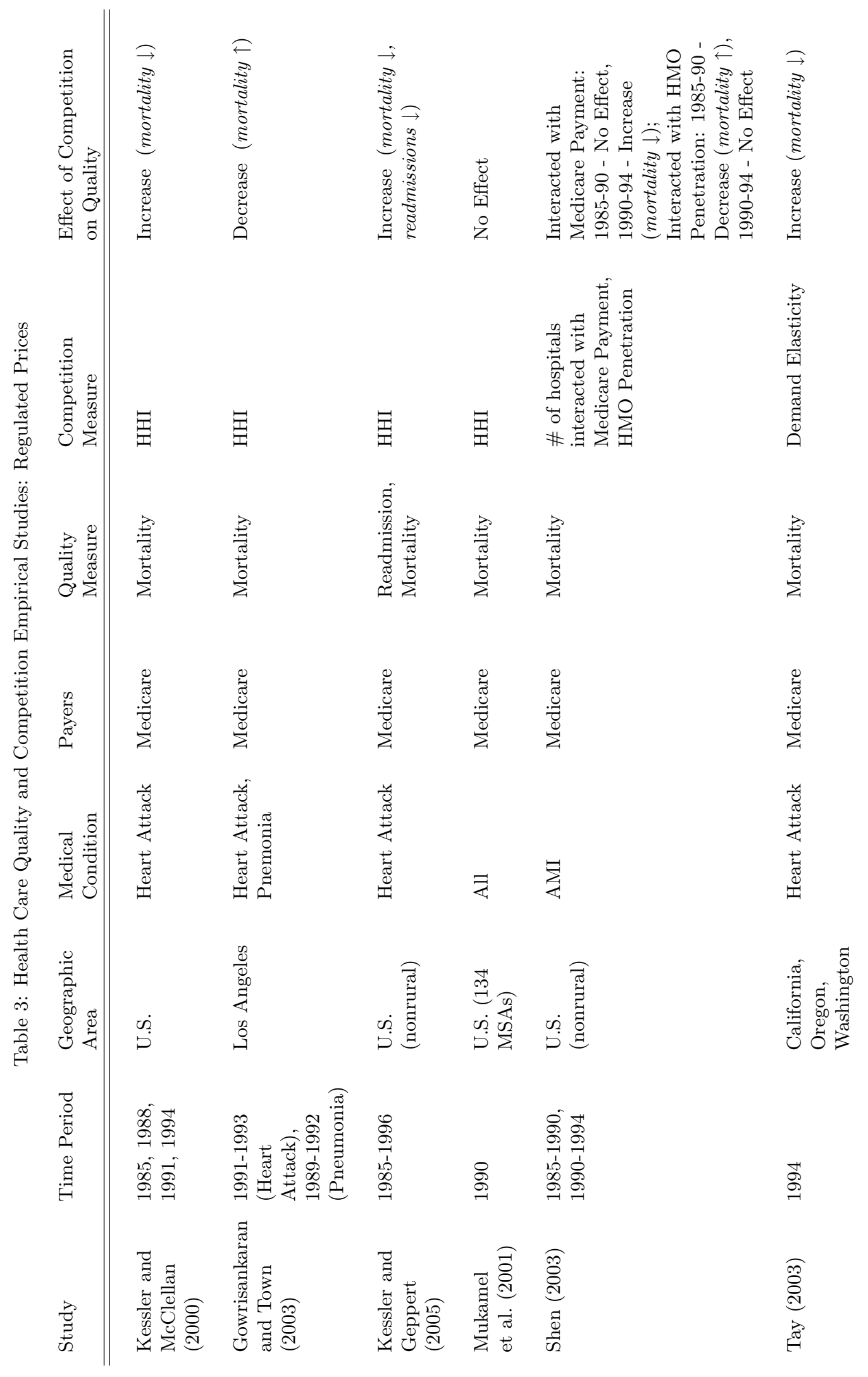




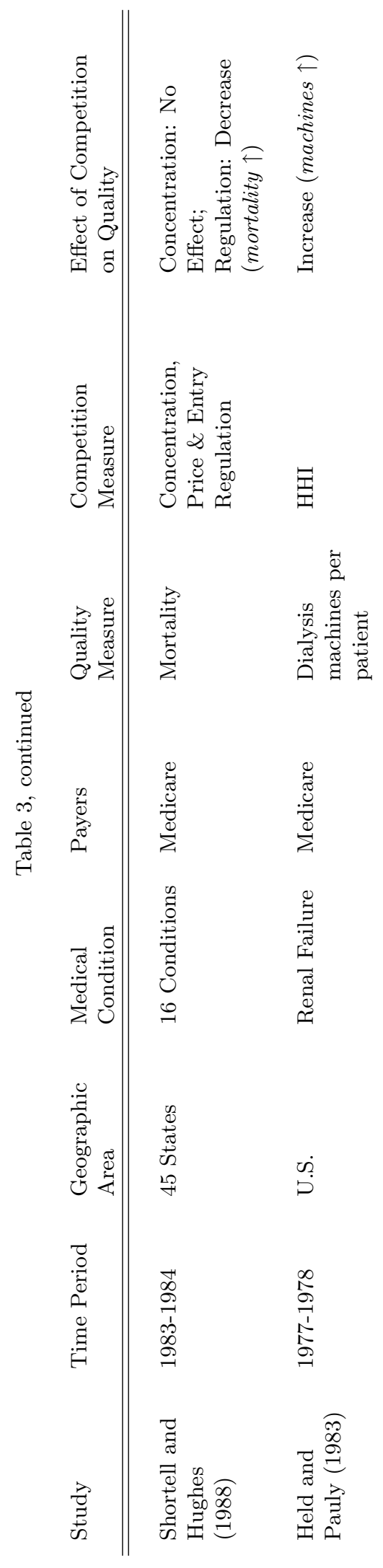




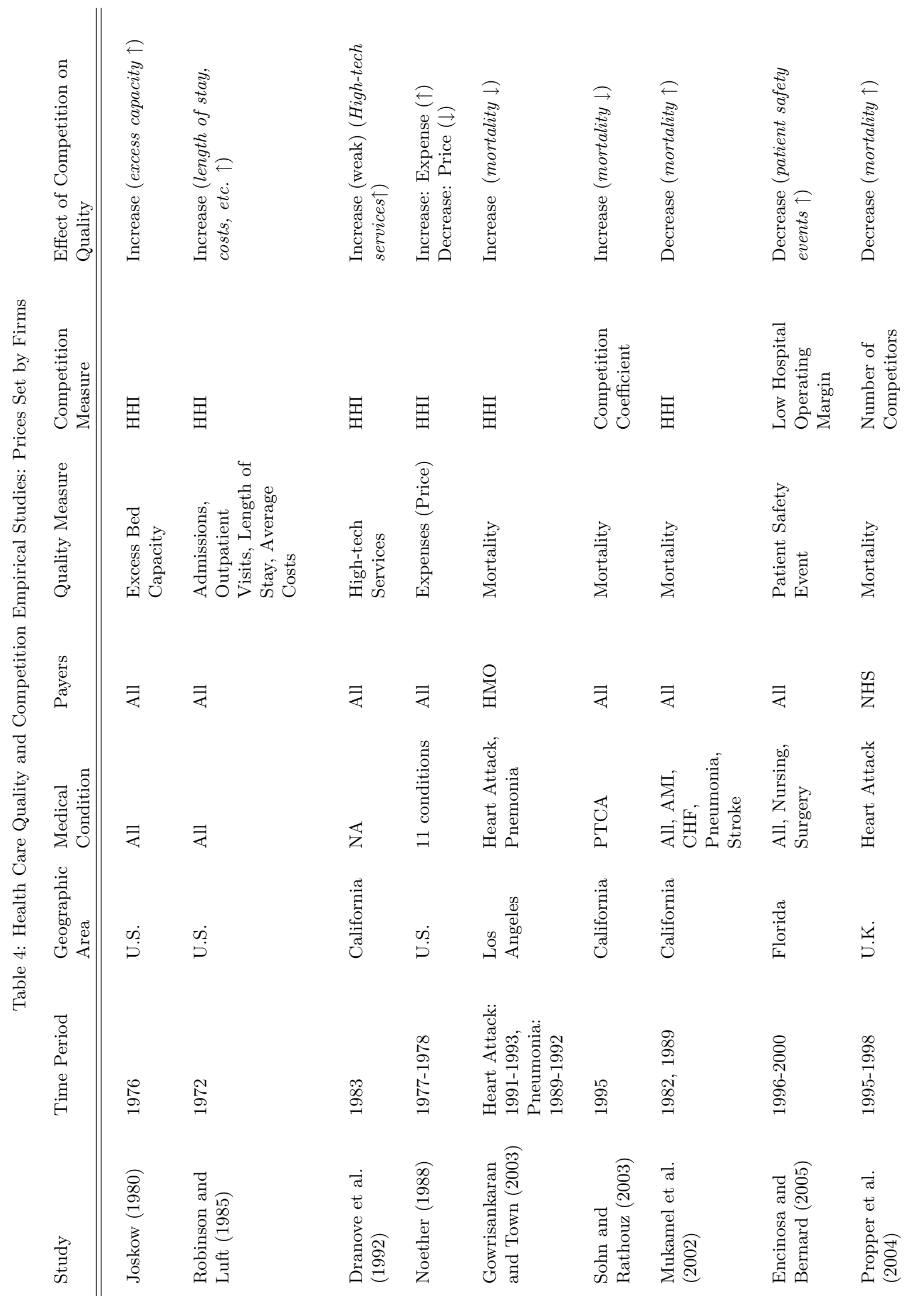




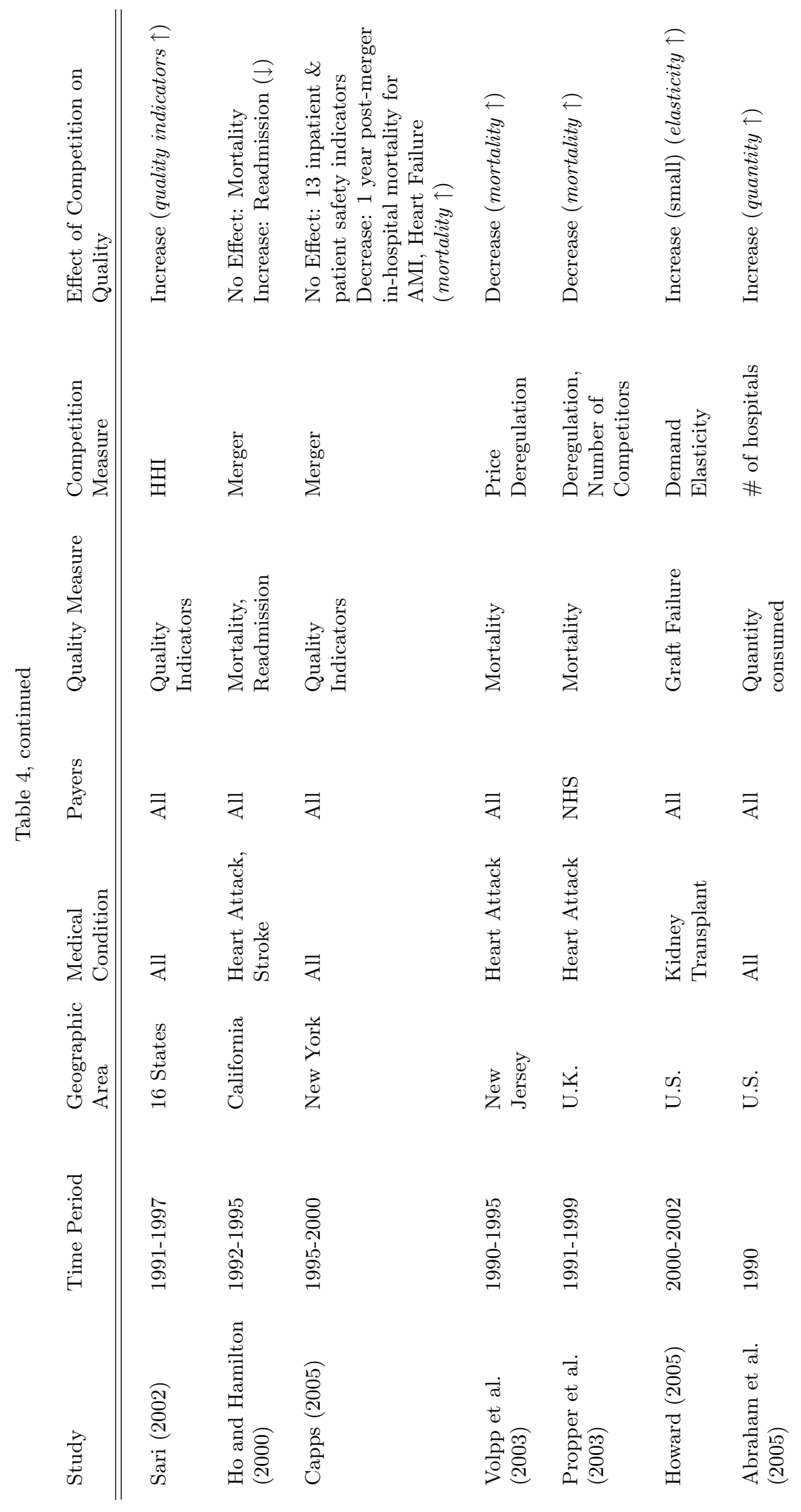




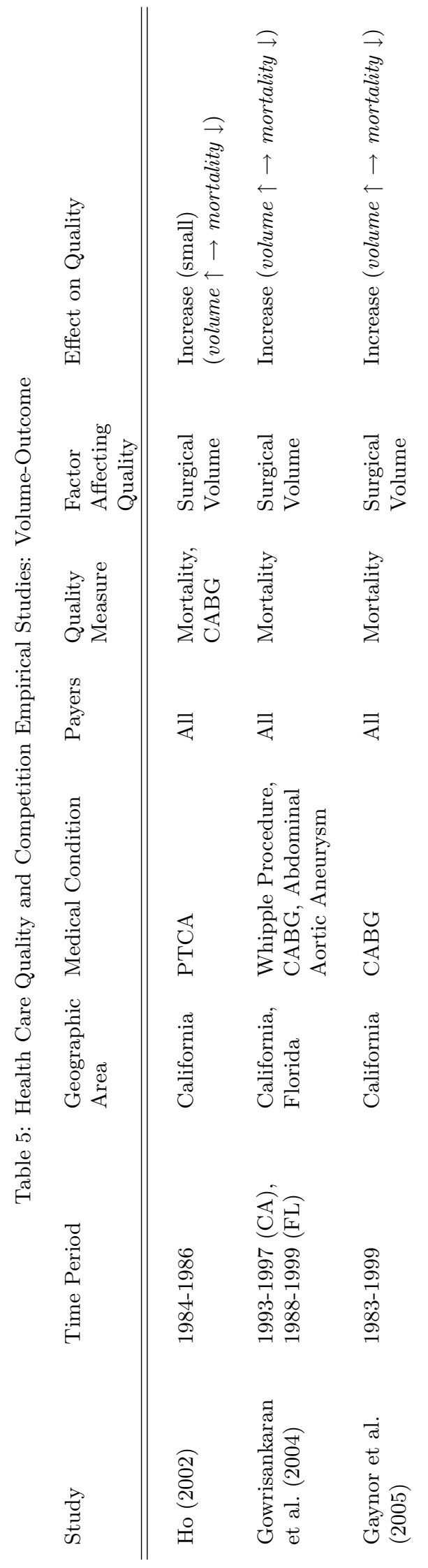

